\title{
A Long-Lasting Mode Water Vortex in the Northeast Atlantic Ocean
}

\author{
GILlES REVERDin AND JEAN-ClAUde GASCARD \\ Université Pierre et Marie Curie, Paris, France \\ BERNARD LE CANN \\ LPO, UMR6523 CNRS/IFREMER/UBO, UFR Sciences, Brest, France \\ LOUIS PRIEUR \\ LOV, UMR7093 CNRS/UPMC, Villefranche-sur-mer, France \\ Michel Assenbaum \\ LEGOS/BRESM, UMR5566 CNES/CNRS/UPS/IRD, Toulouse, France \\ PASCALE LHERMINIER \\ LPO, UMR6523 CNRS/IFREMER/UBO, UFR Sciences, Brest, France
}

Laboratoire d'Océanographie et du Climat: Expérimentation et Approches Numériques, UMR7159 CNRS/IRD/MNHN/UPMC,

(Manuscript received 2 January 2008, in final form 19 September 2008)

\begin{abstract}
An anticyclonic mode water vortex and its environment were investigated from November 2000 to September 2001 in the northeast Atlantic (near $43.5^{\circ} \mathrm{N}, 15^{\circ}-19^{\circ} \mathrm{W}$ ) with neutrally buoyant drifting floats, moored current meters, satellite altimetric sea surface height, and several hydrological surveys and sections. These observations reveal a coherent inner core $(\sim 30 \mathrm{~km}$ in diameter $)$ made of very oxygenated northeast Atlantic central waters $\left(11^{\circ}-12.7^{\circ} \mathrm{C}\right.$ and $35.5-35.7$ on the 1978 practical salinity scale) from $150 \mathrm{~m}$ down to about $750-\mathrm{m}$ depth. The core presents high relative vorticity (up to approximately -0.5 times the Coriolis frequency $f$ ) within at least $10 \mathrm{~km}$ of its center, near $400-700 \mathrm{~m}$. Peak velocity along the core rim is located deeper than 600 $\mathrm{m}$ bordering the deepest and densest $\left(\sigma_{\theta}=27.175 \mathrm{~kg} \mathrm{~m}^{-3}\right)$ northeast Atlantic mode water found during the Programme Océan Multidisciplinaire Méso Echelle (POMME) project. This water likely originates north of $47^{\circ} \mathrm{N}$, where it could have been in contact with the sea surface in early 1999. Below the core, large nearinertial internal waves are found. At least during spring and summer 2001, the core was embedded in a much larger anticyclonic eddy that extends to $100 \mathrm{~km}$ from its center, with azimuthal velocity decreasing from the sea surface to $1500 \mathrm{~m}$. This eddy does not trap floats for a long time and is associated with a sea level anomaly on the order of $10 \mathrm{~cm}$. From January through August 2001, both the core and the larger eddy moved anticyclonically around a shallow part of the Azores-Biscay ridge. The core trajectory also exhibits smaller anticyclonic loops on shorter time scales, suggesting that at least at times it is not located at the center of the larger eddy.
\end{abstract}

\section{Introduction}

One of the main objectives of the Programme Océan Multidisciplinaire Méso Echelle (POMME) experiment

\footnotetext{
Corresponding author address: Gilles Reverdin, LOCEAN, Université Pierre et Marie Curie, Boite 100, 4 Place Jussieu, 75252 Paris CEDEX 5, France.

E-mail: gilles.reverdin@locean-ipsl.upmc.fr
}

was to investigate the mechanisms involved in the formation and subduction of mode waters in the intergyre part of the northeast Atlantic Ocean between the Azores Current and the North Atlantic Drift $\left(38^{\circ}-45^{\circ} \mathrm{N}\right.$; Mémery et al. 2005). Beyond expectation, a complex mesoscale eddy field was found in the POMME domain during the full year of the experiment (Le Cann et al. 2005). Among them, a very coherent anticyclonic eddy, A1, was identified and followed by neutrally buoyant 
(isobaric) floats near 250- and 450-m depths for about 10 months. This anticyclonic eddy presented a particularly coherent submesoscale coherent vortex (SCV) at subsurface [see Lilly and Gascard (2006) for a kinematic description of this SCV based on one float]. The eddy displacement was also noted as rather different from the other eddies identified by the floats. The object of this paper is to further investigate this SCV and its environment.

Coherent eddies from this part of the Atlantic have been studied intensively during the past $15 \mathrm{yr}$. Structures analyzed include meddies (Richardson et al. 1991, 2000; Paillet et al. 2002), which are lens-like eddies centered at intermediate depths that can transport genuine Mediterranean water masses over long distances across the North Atlantic Ocean and often have a near-surface signature (Stammer et al. 1991). Some of these eddies have been identified during POMME, particularly in the southern part of the domain (Le Cann et al. 2005).

Several other types of mesoscale eddies with a surface signature have been observed in the northeast Atlantic in recent years. Some are categorized as slope water oceanic eddies (swoddies), which present maximum intensity in the upper thermocline (Pingree and Le Cann 1992; Paillet 1999). The first well-studied thermoclineintensified eddy was observed during the Tourbillon experiment in 1979 near $47^{\circ} \mathrm{N}$ and $15^{\circ} \mathrm{W}, 120$ miles north of the POMME domain (Le Groupe Tourbillon 1983). Its characteristics were strikingly different from the meddies. The main part of the Tourbillon eddy extended from just the surface down to about $1000 \mathrm{~m}$, so it was mainly concentrated above the main thermocline rather than beneath it in contrast to meddies [although both meddies and Tourbillon-like eddies extend through the whole water column in some cases and belong to the submesoscale coherent vortex family, as defined by McWilliams (1985)]. The Tourbillon-like eddy core was mainly composed of northeast Atlantic central mode waters, and the Mediterranean layer was depleted just underneath its core. Similar vertical structures have also been observed in the Iceland basin, both for the intense Plankton Reactivity in the Marine Environment (PRIME) eddy (Martin et al. 1998; Wade and Heywood 2001), and for the 1998 eddy of Read and Pollard (2001). These eddies are all mode water eddies. Other examples of subsurface-intensified eddies in the eastern subtropical Atlantic have been described by Pingree (1996), although with a shallower core as mode waters south of the Azores Current are found much shallower than those further north in the eastern Atlantic. This region is also the site of surface-intensified cyclonic eddies referred to as subtropical oceanic rings of magnitude (STORM; Pingree and Sinha 1998) eddies, which probably have their origin in the instabilities of the Azores Current. There are summer observations suggesting that anticyclonic mode water eddies are the site of intensified biological production (for a swoddy, see Garcia-Soto et al. 2002). This could be caused by the doming of the seasonal thermocline over the center of the eddy, resulting from the interaction between surface currents and surface wind, as discussed by McGillicuddy et al. (2007) for the intense western subtropical Atlantic eddy A4 in 2005.

In this paper, we will provide an analysis of the wellobserved POMME anticyclone A1. After briefly presenting the main datasets used, we will discuss the SCV characteristics:its trajectory, its hydrological and water mass properties, and its three-dimensional velocity structure. Then we will present the surrounding mesoscale eddy. Finally, we will discuss how closely the two structures are linked, their origin, and their interaction with bathymetry.

\section{Dataset presentation}

The dataset used here includes primarily 1) trajectories of neutrally buoyant (isobaric) float trajectories; 2) a high-resolution CTD/vessel-mounted acoustic Doppler current profiler (VM ADCP) section on 30 April 2001, one expendable CTD (XCTD)/VM ADCP section on 6 March 2001, and CTD/lowered ADCP (LADCP) profiles collected during the three POMME surveys between February and September 2001; and 3) current data from two moorings (northeast and northwest moorings) at the depths 400 and $1000 \mathrm{~m}$. In addition, we use the 7-day standard sea level anomaly products delivered by CLS Argos in Toulouse (Ducet et al. 2000) to complement the large-scale view of the eddy. A more general presentation of the POMME datasets is found in Mémery et al. (2005).

\section{a. Lagrangian data}

Several floats drifted in the vicinity of eddy A1 (Le Cann et al. 2005) among many floats launched between September 2000 and March 2001 in the context of POMME and a few more floats launched during other projects (e.g., Arcane, Eurofloat; Le Cann et al. 1999). A list of the floats and when they sampled A1 or its eddy core as well as their average depth is reported in Table 1. The floats are of different types, either subsurface acoustically positioned floats, or surface floats drogued at different depths and localized either with a GPS (Surdrift 24331, drogued at $400 \mathrm{~m}$ ) or with Argos (Carioca 01110, drogued at $15 \mathrm{~m}$, or Marisonde 15501, with a $100-\mathrm{m}$ chain in the water). 
TABLE 1. Principal floats having stayed in the circulation of A1 for a while or in the SCV. MV indicates Marvor; VCM and SV are two types of RAFOS floats.

\begin{tabular}{lclc}
\hline \hline \multicolumn{1}{c}{ Float ID } & Depth $(\mathrm{m})$ & & Dates near A1 \\
\hline MV 19954 & $400-500$ & & Dates within SCV \\
VCM 30 & $240-365$ & & 6 Mar to 10 Sep 2001 2000 to 15 Aug 2001 \\
Surdrift 24331 & 400 & 7-11 Mar 2001 & 11 Feb 2001 to 23 Mar 2001 \\
SV 108 & 1050 & 6-15 Feb 2001, 1 Jun to 31 Aug 2001 & \\
VCM 19 & 140 & 20 Dec 2000 to 9 Jan 2001, 4 Feb to 10 Mar 2001 & \\
VCM 65 & 100 & 10-20 May 2001 & \\
MV 12 & 400 & 20 Dec 2000 to 9 Jan 2001 \\
SS 113 & 450 & 30 Feb to 21 Mar 2001 & \\
SS 114 & 450 &
\end{tabular}

The acoustically positioned floats were different types of sound fixing and ranging (RAFOS, which is SOFAR spelled backwards) floats, located underwater with long-range SOFAR acoustic signals transmitted by sound sources installed on moorings. Marvor floats are equipped with an automatic ballast control system, and MV 19954 is set so that the drifting depth ranges between 400 and $500 \mathrm{~m}$. They are also programmed for a certain time at depth (for MV 19954, it was three months), after which they rise to the surface (for up to three days) to transmit data to Argos before diving again to the prescribed depth. The depth of the other types of RAFOS floats was not actively controlled, and it was estimated from a pressure sensor. Some of these sensors did not work properly, but when they did, the float depth usually remained within a 100-m range. Some of the floats were designed to measure vertical velocities [Vertical Current Meter (VCM) floats]. They were operated at $780 \mathrm{~Hz}$ and were located every $4 \mathrm{~h}$ (e.g., RAFOS VCM 30; Lilly and Gascard 2006). The other RAFOS floats were operated at $260 \mathrm{~Hz}$ and were usually located every 8 h (MV 19954 was located once a day). The surface floats were Argos located, and the Surdrift buoys also had hourly GPS positions. The absolute accuracy for locating floats underwater was estimated as $3-5 \mathrm{~km}$ (Le Cann et al. 2005), whereas it is better than $1 \mathrm{~km}$ for surface drifters and $100 \mathrm{~m}$ for the Surdrift float.

Two subsurface floats-MV 19954 and VCM 030remained trapped in the SCV looping at periods of 3-5 days (between 425 and 500, and near $250 \mathrm{~m}$, respectively), from 15 November 2000 (near $43^{\circ} 30^{\prime} \mathrm{N}, 15^{\circ} 30^{\prime} \mathrm{W}$ ) to 15 August 2001 (three complete 3-month cycles) and from 6 March 2000 (deployment in the SCV core at $43^{\circ} 15^{\prime} \mathrm{N}, 17^{\circ} 30^{\prime} \mathrm{W}$ ) to 10 September 2001 , respectively, and then they returned to the sea surface. Some surface drifters were deployed in the vicinity of the SCV, and remained for a while near its core (23 March; Merlivat et al. 2009). One RAFOS float, SV 108, was deployed at the same time as VCM 030, $20 \mathrm{~km}$ from the SCV center and drifted near $1050 \mathrm{~m}$. It remained in the eddy from March 7 to November 2001. Other floats that were not deployed in the SCV drifted at times in the mesoscale eddy circulation for up to two months. They are also listed in Table 1.

\section{b. Hydrological data}

Two transects crossed the SCV core. On 6 March 2001 (P1), the French Navy Research Vessel D'Entrecasteaux did a west-east transect of A1 between $18^{\circ} 20^{\prime}$ and $16^{\circ} 30^{\prime} \mathrm{W}$ at about $43^{\circ} 20^{\prime} \mathrm{N}$ with $150-\mathrm{kHz}$ VM ADCP current data to at least $300 \mathrm{~m}$ and launching XCTDs every $13 \mathrm{~km}$, providing temperature $(T)$ and salinity $(S)$ profiles to at least $1500 \mathrm{~m}$. They intersected well with the SCV (with the closest position some $2 \mathrm{~km}$ north of its core): XCTD 168, $4 \mathrm{~km}$ from the center and XCTD $167,10 \mathrm{~km}$ from the center. This took place during a storm on the day when the coldest surface temperature was reported at about $0800 \mathrm{LT}$ by the three surface drifters trapped in the eddy (the reports range between $12.72^{\circ}$ and $12.76^{\circ} \mathrm{C}$ and a drifter-measured surface salinity of 35.705 on the 1978 practical salinity scale, hereafter pss-78).

On 30 April, eddy A1 was intersected by the R/V Atalante during a $43^{\circ}-44^{\circ} \mathrm{N}$ tow-yo CTD section along $18.50^{\circ} \mathrm{W}$, providing profiles of temperature, salinity, and oxygen down to $700 \mathrm{~m}$ with a nearly 1-km horizontal resolution (the SCV center was then at $43.645^{\circ} \mathrm{N}$, $18.43^{\circ} \mathrm{W}$, therefore $6 \mathrm{~km}$ away to the east of the section). The R/V Atalante $75-\mathrm{kHz}$ VM ADCP also provided an almost-complete section of currents to at least $600 \mathrm{~m}$.

Within the 56-km resolution station array completed during leg 1 of each POMME cruise (P1, February 2001; P2, April 2001; P3, September 2001; Mémery et al. 2005), the core of A1 was sampled by a CTDLowered Acoustic Doppler Current Profiler (LADCP) cast down to 2000-m depth (23 of P1, 41 of P2, and 26 of P3). There were other CTD-LADCP casts done during either leg 1 or leg 2 of the cruises P1, P2, and P3 
that were farther from the core of the eddy and did not always reach $2000 \mathrm{~m}$. During all these casts, additional (chemical, biological, or bio-optical) measurements were collected. The 150-kHz downward-looking LADCP data were processed using the inverse method of Visbeck (2002) and provided current profiles binned every 16 to roughly $200 \mathrm{~m}$ below the bottom of the cast.

\section{c. Eulerian data}

Current meters (hourly samples) at two levels-near 350-400- and 950-1000-m depth-will be used from two moorings, which were crossed by eddy A1. The eastern (NE) mooring was located at $43^{\circ} 36^{\prime} \mathrm{N}, 17^{\circ} 21^{\prime} \mathrm{W}$ and the western (NW) mooring at $43^{\circ} \mathrm{N}, 19^{\circ} 04^{\prime} \mathrm{W}$. These two moorings were deployed in February 2001 during P1 (leg 1) and recovered at the end of August 2001 (P3). The eastern mooring was twice within the SCV and remained within eddy A1 in February-March and from mid-May through August, whereas mooring NW was within eddy A1 in April.

\section{d. Altimetric sea level maps}

We use the segment sol multimissions d'altimétrie, d'orbitographie et de localization precise/data unification and altimeter combination system (SSTALTO/ DUACS) multisatellite-mapped sea levels and currents (Le Traon et al. 2001) at a 7-day interval. For the POMME period, we use the European Remote Sensing Satellite (ERS) ERS-2, Ocean Topography Experiment (TOPEX)/Poseidon and Geosat Follow-On (GFO) satellite altimetric data, which are expected to resolve scales on the order of $50-100 \mathrm{~km}$. The variable part of the field is produced by objective mapping with an exponential time scale of 15 days, and an average field is added to the altimetric sea level.

\section{SCV}

We will first describe the SCV and its displacements from floats trapped into it during the POMME year. We will then use the sections across the SCV to characterize water masses and have a first hint at horizontal velocity structure across the eddy. This will be followed by a summary of the water masses at CTD stations located in the core during the surveys. The vertical current structure will then be examined from LADCP data, float velocities at different depths will be compared, and evidence for large near-inertial oscillations below the thermocline under the core will be discussed. Often, as in the next sections, dates will be reported in calendar dates (day $1=1$ January 2001).

\section{a. SCV positions}

The two floats (MV 19954 and VCM 030) trapped in the SVC are used to follow its displacement from 15 November 2000 to 10 September 2001. Their looping trajectories (not shown) indicate that they remained within 5-20 km of a rotation center, suggesting that the SCV had a radius of at least $20 \mathrm{~km}$ (see the more detailed analysis on VCM 30 trajectory in Lilly and Gascard 2006). In contrast, Surdrift 24331 (a surface drifter drogued at $400 \mathrm{~m}$ ), which made 7 loops with a velocity of roughly $20 \mathrm{~cm} \mathrm{~s}^{-1}$ (between 8 and $17 \mathrm{~km}$ from its center), was ejected after 40 days from a distance to the center of roughly $17 \mathrm{~km}$, but this might be due to a small contribution of near-surface currents to the velocity of this drifter.

These trajectories show that the radius over which the SCV traps the floats was at least $15 \mathrm{~km}$. From the trajectories, and assuming that the velocity combines a rotation at a constant rate around the center with a translation, a position of the center of rotation is estimated. A more sophisticated method applied to VCM 30 position data in Lilly and Gascard (2006) yields similar results. This is done each day for each float. Typically, the center of rotation of MV 19954 tends to be positioned westward/southwestward with respect to the shallower VCM 30 by $2-5 \mathrm{~km}$. This might be partly because MV and VCM floats have different tracking systems operating at different ranges and frequencies. However, a VM ADCP current section across the SCV obtained on 6 March 2001 by the R/V d'Entrecasteaux also revealed an inclination of the axis of rotation of about $1 \mathrm{~km}(100 \mathrm{~m})^{-1}$ (equivalent to about $2 \mathrm{~km}$ for the two floats separated by about $200 \mathrm{~m}$ along the vertical). We create a unique time series when combining the two floats (Fig. 1): we first estimate the average difference in position, then shift each time series by half this difference, and then average the two corrected positions during the period of joint drift. The resulting position of the center can be checked for days 43-79 of 2001 with the one estimated from Surdrift 24331. The two estimates are usually within $3 \mathrm{~km}$ of each other (the larger difference on days $43-50$ might be related to surfacing of MV 19954 on day 45). This comparison yields an upper range of what the uncertainties are on the time series of center position.

The vortex trajectory (Fig. 1) is not regular. It presents relatively small anticyclonic loops (20-50-km diameter) from mid-December 2000 through August 2001, embedded within a broader anticyclonic (clockwise) displacement around the large-scale bathymetric feature of the Azores-Biscay ridge. The displacement velocity of the core position varies greatly and can reach or exceed 


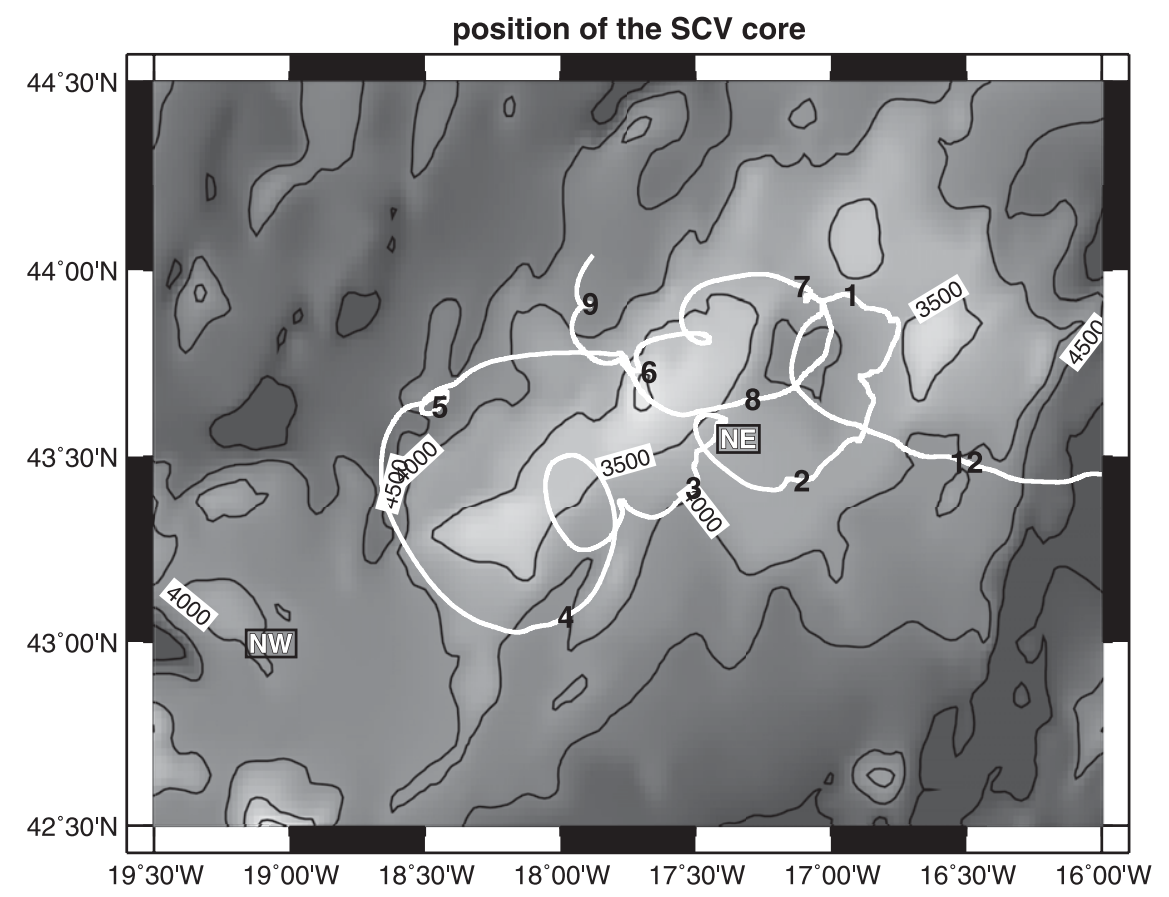

FIG. 1. SCV center position (white line) from November 2000 until September 2001 superimposed on bottom topography (light above $3500 \mathrm{~m}$, which corresponds to a segment of the Azores-Biscay ridge). The month number (in black) is reported on the curve at beginning of each month. Two current meter moorings locations are indicated (NE and NW). See text for explanations on how the SCV center position is estimated from two float trajectories.

$5 \mathrm{~cm} \mathrm{~s}^{-1}$ at times, in particular in April. Although we have no precise location of the SCV core after 6 September, RAFOS 108 trajectory (at depth $\sim 1000 \mathrm{~m}$ ) suggests that later, until early November 2001, the eddy moved southwestward along the northern flank of the ridge feature. This is also coherent with the eddy A1 trajectory derived from altimetry (refer to the appendix).

\section{b. Sections across the SCV}

The high-resolution tow-yo section crossing the SCV a few kilometers west of its center on 30 April provides a unique opportunity to document the SCV core down to $700 \mathrm{~m}$. Figure 2 presents the potential density (contours) and oxygen (color) section. Around the SCV core, found that day at $43.64^{\circ} \mathrm{N}$, there is a doming of the isopycnals between 100 and $600 \mathrm{~m}$ and an indication for a dip below. This structure implies, in particular, an area of weak stratification (squared buoyancy frequency $N^{2}$ less than $2 \times 10^{-6} \mathrm{~s}^{-1}$ ) centered at $650 \mathrm{~m}$. The oxygen plot indicates clearly that this core is anomalously rich in oxygen compared to its environment (on density surfaces), at least below $300 \mathrm{~m}$. The oxygen maximum at a depth of $650 \mathrm{~m}$ corresponds to a very oxygenated water [maximum at $93 \%$ of the saturation value, which implies an apparent oxygen utilization (AOU) of 17 $\left.\mu \mathrm{mol} \mathrm{kg}{ }^{-1}\right]$. This water is centered on $\sigma=27.175$ at potential temperature of $11.16^{\circ} \mathrm{C}$ and $S=35.55$.

In addition to this mode water, the vertical profiles in the core suggest a slightly lesser stratification near 350$400 \mathrm{~m}$, associated with a slightly higher saturation ratio than just above or below it with a potential density $\sigma=$ $27.08\left(12^{\circ} \mathrm{C} / 35.62\right)$. Closer to the surface near $200 \mathrm{~m}$, there is another region of weaker stratification (but no contrast with the outlying areas at the same density). This one centered at $\sigma=26.995, T=12.7^{\circ}-12.8^{\circ} \mathrm{C}$, and $S=35.71$ is a clear remnant of the deep winter mixed layer (surface measurements from drifters indicate that minimum late winter surface $T$ in the SCV core ranged between $12.72^{\circ}$ and $12.76^{\circ} \mathrm{C}$ for $S=35.705$ ).

This section done at a very high-horizontal resolution (on the order of $1 \mathrm{~km}$ ) identifies a transition region between these very particular core properties and the outlying area, with probably a radius range as large as the one of the SCVs. This is illustrated in Fig. 3 with the oxygen profile across the SCV indicating a plateau near the center, followed by a region of high horizontal gradients (the transition domain), indicating the exchange between the core and the outskirt. On the zonal velocity profile, the first region (core) corresponds to a region with constant meridional shear, suggesting solid body rotation with relative vorticity near the 


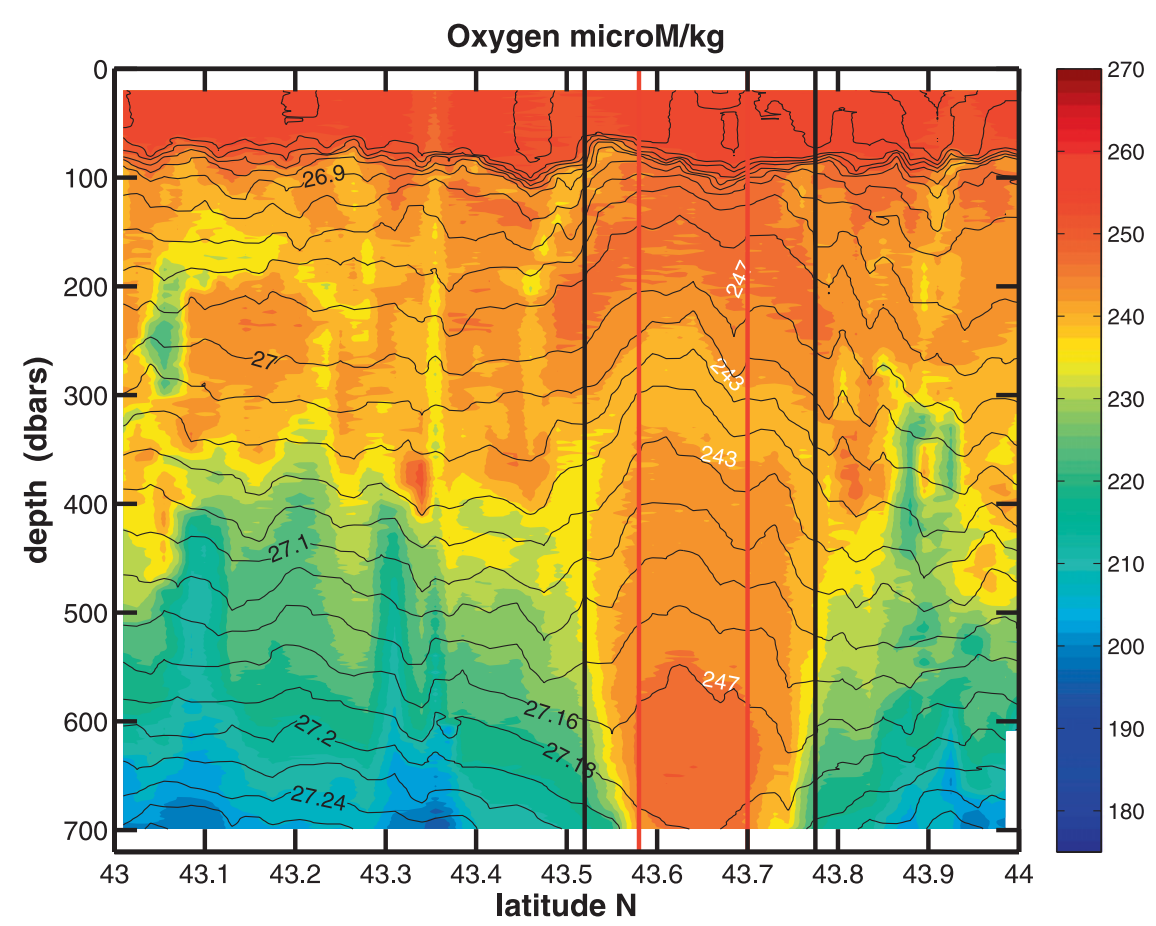

FIG. 2. The 30 April north-south tow-yo CTD section of the R/V Atalante passing some 5-6 $\mathrm{km}$ to the west of the SCV center at $43.64^{\circ} \mathrm{N}$ (profiles every $1 \mathrm{~km}$ ). The plot is for potential density (contours) and oxygen ( $\mu \mathrm{M} \mathrm{kg}^{-1}$; color). The red lines indicate roughly the eddy core boundaries, and the black line is the limit of the intermediate region.

center close to $\zeta=-0.5 f$ ( $f$ is the Coriolis frequency). In the core of large relative vorticity, and also because of weak stratification near $600 \mathrm{~m}$, potential vorticity is as low as $0.510^{-11} \mathrm{~m}^{-1} \mathrm{~s}^{-1}$. The transition domain, on the other hand, includes the velocity maximum where relative vorticity is less than half the core value. A single section is too noisy to allow a more refined computation of relative or potential vorticity profiles.

A similar structure is present in the lower-resolution XCTD section of 6 March. Close to the SCV center, it also presents a minimum stratification near $600 \mathrm{~m}$ (indicative of the mode waters illustrated on Fig. 2) and a doming/deepening of isopycnals above/below it (Fig. 4). This section taken on the day of densest surface water (and after a strong wind event) is also probably indicative of the deepest mixed layers encountered by the SCV in 2001. This shows a slight shoaling of mixed layer depth above the core $(180 \mathrm{~m})$, with the deepest mixed layers $(250-260 \mathrm{~m})$ found roughly $40 \mathrm{~km}$ from the core. The XCTD section extends everywhere at least to 1500 $\mathrm{m}$. At that time, the deep structure (900-1300 m) also presents a maximum of temperature-salinity $(T-S)$ on isopycnals near the core, indicative of a larger contribution of Mediterranean water to the core than farther away. This is the day that float SV 108 was dropped into the eddy near $1055 \mathrm{~m}$ with a temperature (and distance to center) suggestive that it floated in this water mass. Rather surprisingly, the float was not tightly trapped in the core, which it left by late March, and then wandered at greater distances from the center and in water with less Mediterranean influence. Later (day 140) it drifted back at $20-30 \mathrm{~km}$ from the center but did not exhibit the initial pronounced presence of Mediterranean water. Clearly, at these depths there was an active exchange between the water near the SCV core and the outskirts of the vortex.

\section{c. Individual stations in the SCV}

Additional hydrological data in (or close to) the core are from leg 1 stations 23 (P1; 15-20 km from center), 41 (P2; $8 \mathrm{~km}$ from center), and 26 (P3; $13 \mathrm{~km}$ from center). This can be used to see how much the characteristics that we have just described based on the high-resolution section are seen at other times. These stations have contrasting properties to the CTD stations on the outskirts of the eddy-for example, 157 to 180 taken on 13-14 March 2001 (to the east of the SCV), as will be discussed below.

The dissolved oxygen vertical distribution presents an inner core with a very high concentration down to about $800 \mathrm{~m}$ and a peak value at 600-m depth (Fig. 5). Compared to the other hydrological stations taken during 
600-700 dbar averaged Oxygen

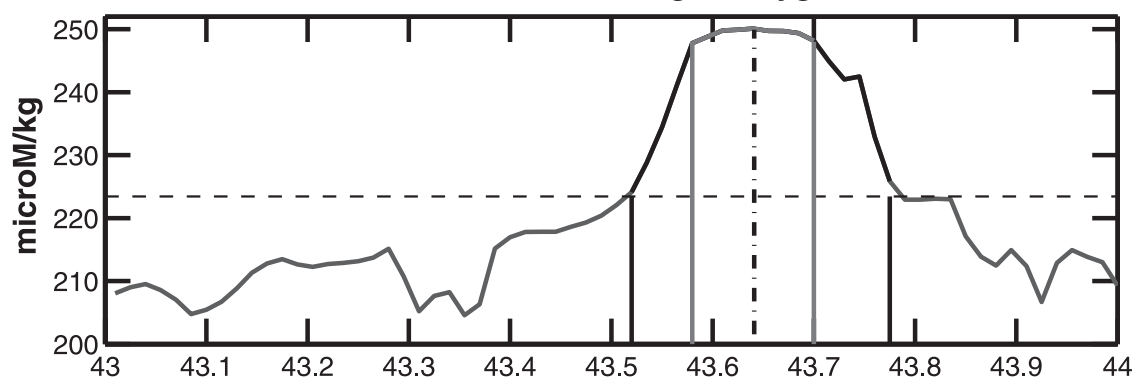

Eastward component of absolute current

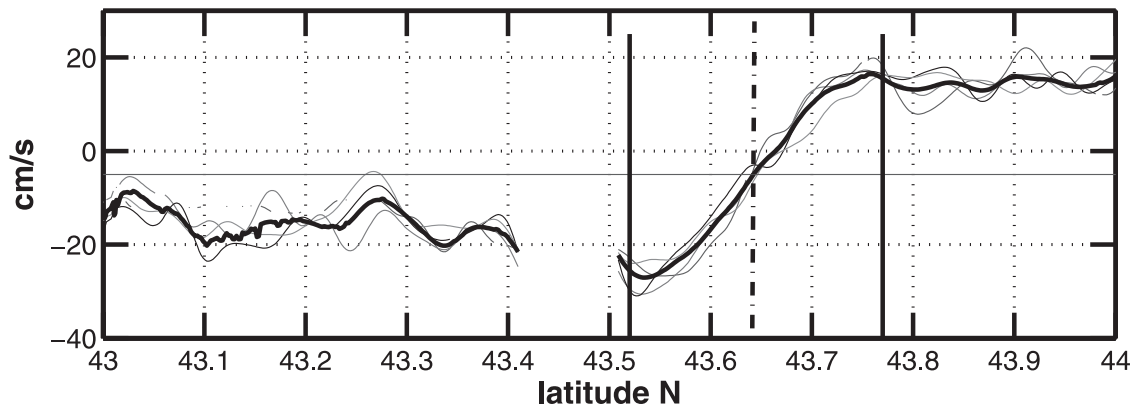

FIG. 3. The 30 Apr $2001 \mathrm{R} / \mathrm{V}$ Atalante meridional section west of the eddy center. (top) Average oxygen in the 600-700-dbar layer in which the oxygen maximum is found. (bottom) Zonal velocity from the ship VM ADCP at different depths (the thick line is for the average, $445-621 \mathrm{~m}$ ). The vertical lines indicate roughly the position closest to eddy core (mixed line): (top) the edge of the homogeneous core, and (bottom) the location of the velocity maxima. Notice that the center of the SCV seems to correspond to a westward zonal velocity of $-4 \mathrm{~cm} \mathrm{~s}^{-1}$ (horizontal line in bottom panel), in accordance with the translation estimates of the core at that date based on the floats.

the POMME experiment, this corresponds to a strong positive anomaly in the dissolved oxygen vertical distribution. Its maximum is found on the potential isopycnal surface $\sigma_{0}=27.175$, which presents much lower oxygen at surrounding stations. The corresponding ratio of oxygen saturation is close to $93.7 \%$ near $600 \mathrm{~m}$ during P2 and more than 91\% during P3 (AOU of 15.6 and $24 \mu \mathrm{mol} \mathrm{kg}{ }^{-1}$ ). In comparison, the value during $\mathrm{P} 1$ is slightly less at this depth, even on the same density horizon, which is a little shallower for the $\mathrm{P} 1$ profile. This implies that this P1 station farther from the center is within the transition region. The three stations also present in this layer a lesser stratification than for the other profiles (Fig. 6), with minimum stratification found at the same level as the maximum oxygen for stations 41 $(\mathrm{P} 2)$ and $26(\mathrm{P} 3)$. The minimum stratification is also seen in the layer $\sigma_{0}=27.175-27.18$ for the two XCTD profiles closest to the center on 6 March (not shown). On the other hand, this water has a similar $T-S$ relationship to nearby stations (see Fig. 7 for $\sigma_{1}$ near 31.5), corresponding to a dense variety of northeast Atlantic central water. The density of that layer does not correspond to surface water density during the winter 2000/01 in the POMME region (Reverdin et al. 2005). Furthermore, the deepest mixed layer during the winter 2000/01 within the POMME domain, which were observed near its northwest corner and near the northern domain boundary (Bouruet-Aubertot et al. 2005), never exceeded $400 \mathrm{~m}$ in contrast with the $600 \mathrm{~m}$ or more depth of this low stratification water. Data from an earlier cruise in the same area in April 2000 also indicate that surface water at that density was not found in 2000. All these data point to an earlier origin of this water away from the POMME area.

To identify specificities below the core of the SCV at depths of 1000 dbar or deeper, we will now compare properties of these individual core profiles to an average of all profiles outside of the core and within $200 \mathrm{~km}$ of the SCV position in $\sigma_{1}$ (potential density referred to 1000 dbar) coordinate (Fig. 7). The lower panels show that the density profile deviates from the surrounding region between 500 and $1500 \mathrm{~m}$. For water denser than $\sigma_{1}=31.6$ or $\sigma_{0}=27.2$ (deeper than $600 \mathrm{~m}$ ), there is a large density range with large downward isopycnal 


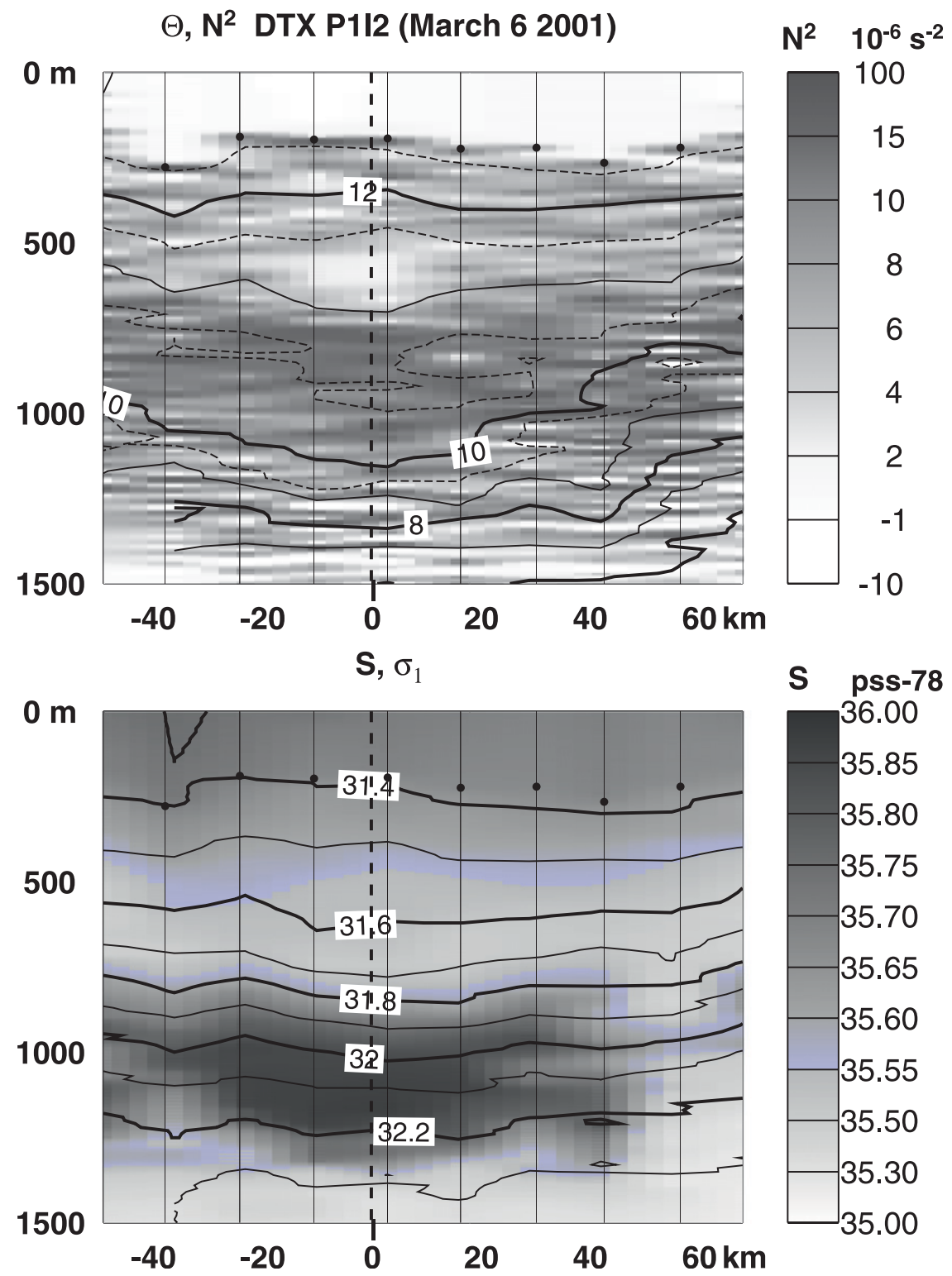

FIG. 4. Zonal sections from XCTDs launched by the R/V d'Entrecasteaux cutting the eddy, less than $2 \mathrm{~km}$ north of its center on 6 Mar. The horizontal axis is zonal distance from the eddy center (indicated by a vertical dashed line), and vertical lines indicate where XCTDs were launched. The dots indicate the depth of mixed layer (based on a SST $-0.1^{\circ} \mathrm{C}$ criterion). The section was done during and after a large wind event and when the surface density was the highest based on drifter data. (top) Potential temperature (lines) with Brunt-Väisälä frequency (grayscale) and (bottom) potential density $\sigma_{1}$ (with 1000-dbar reference level) and salinity (grayscale).

displacements reaching more than $100 \mathrm{~m}$. There are also significant positive temperature and salinity anomalies on these dense isopycnal surfaces peaking in the Mediterranean water layer (up to 0.2 pss-78 for $S$ ). This is particularly pronounced during P1 close to $\sigma_{1}=32$, somewhat above the salinity core at $\sigma_{1}=32.15$. There is an apparent decrease in $T$ and $S$ anomalies at P2 near that level, at all levels during P3 (Fig. 7), confirming that the Mediterranean water present earlier has been largely replaced.

\section{d. Velocity vertical structure above the core depth}

In this section, we will adopt a cylindrical coordinate system with the origin at the SCV center and discuss the 

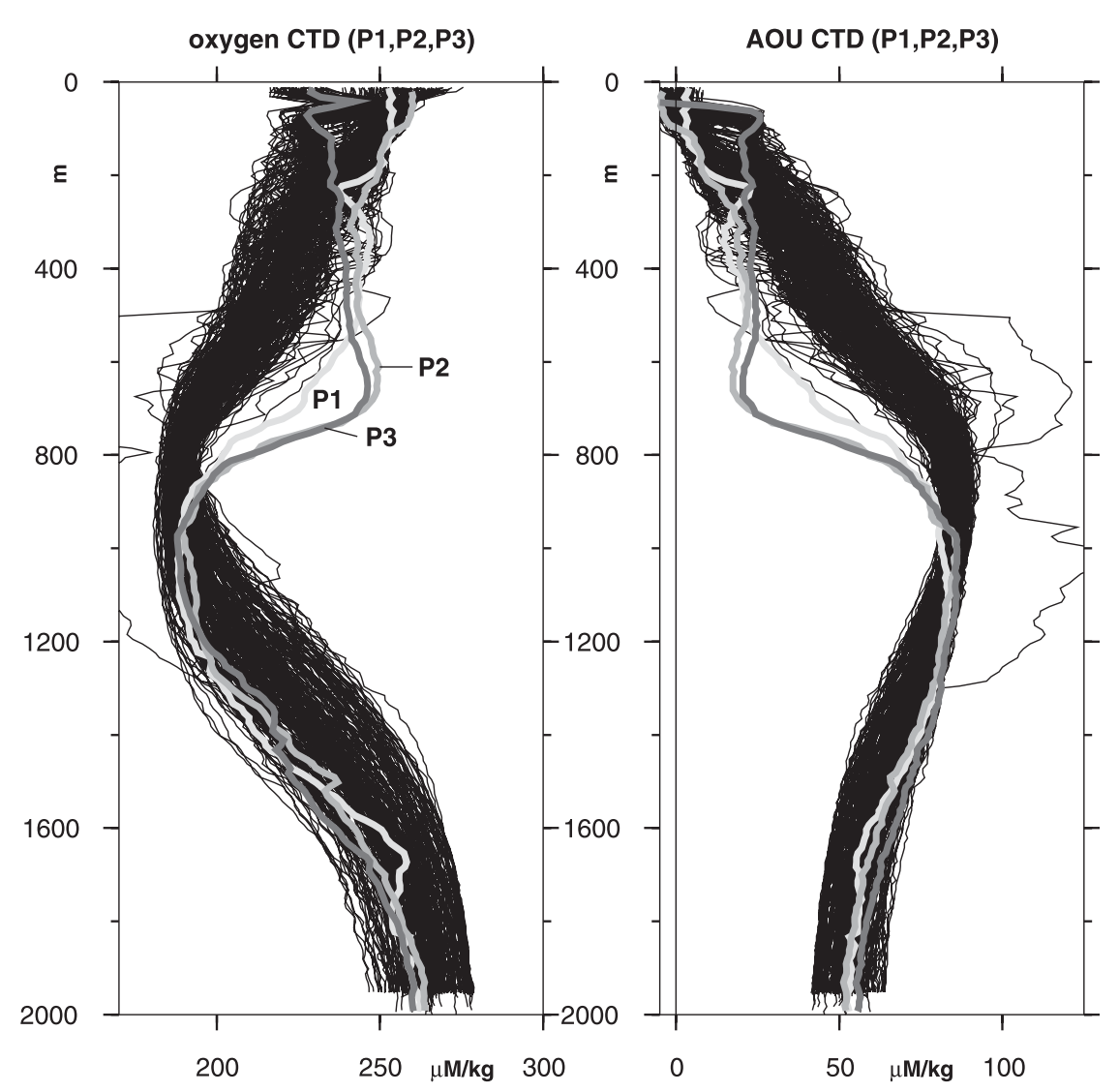

FIG. 5. Vertical profiles of dissolved oxygen $\left(\mu \mathrm{M} \mathrm{kg}^{-1}\right)$ as a function of pressure from 0 to 2000 dbars for all CTD casts $(>80)$ taken during leg 1 of P1 (February), P2 (April), and P3 (September) in 2001. Also CTD casts 23 (leg1, P1), 41 (leg1, P2), 26 (leg 1, P3) collected in the SCV core (close to VCM 030 and MV 19954).

azimuthal velocity component. This assumes that there is symmetry by rotation, an assumption not quite true, as discussed in Lilly and Gascard (2006). The two highresolution density sections indicate by thermal wind (not shown) that there should be a decrease of the cyclostrophic currents above the deep (600-650 m) mode water core. This decrease was not observed in the VM ADCP current section of 30 April between 650 and 350 m (Fig. 3) but that may be due to higher frequency variability.

The floats trapped at different depths provide some indication of the azimuthal velocity vertical profile, but it is only between the MV 19954 (450 m) and the VCM $30(250 \mathrm{~m})$ levels that there is enough data to provide a reliable comparison. Data during the relatively short joint period clearly indicate that velocity at 250 is less than at $450 \mathrm{~m}$ (assuming that the two are within a solid core rotation region). To have more robust statistics, we combine all the velocity estimates during the 10 months of data to construct an azimuthal velocity section across the SCV (Fig. 8). This uses the fact that the float's dis- tance to the center evolves in time at both depths (for MV 19954, in particular, this is caused by the time spent at the surface every 3 months), although the floats clearly remain in the core or close to the core. The assumption that the velocity field has not evolved much in the upper part of the SCV during the POMME year is supported by the floats (Fig. 6 of Lilly and Gascard 2006). These velocity estimates as a function of distance to center show some scatter at both depths [including, particularly, the effect of position errors and the possibility examined in detail in Lilly and Gascard (2006) that trajectories are on an ellipse and not on a circle]. However, the two distributions do not overlap, indicating that velocity at $250 \mathrm{~m}$ might be roughly $30 \%$ less than near $450 \mathrm{~m}$ (Fig. 8). They both indicate a maximum velocity farther than $13 \mathrm{~km}$ from the estimated center.

Based on the thermal wind deduced from hydrographic data, we expect that the cyclostrophic currents at the surface are weaker. However, the two surface drifters, Marisonde 15501 and CARIOCA 01110, trapped in the core between days 42 and 65 (Fig. 9), also 

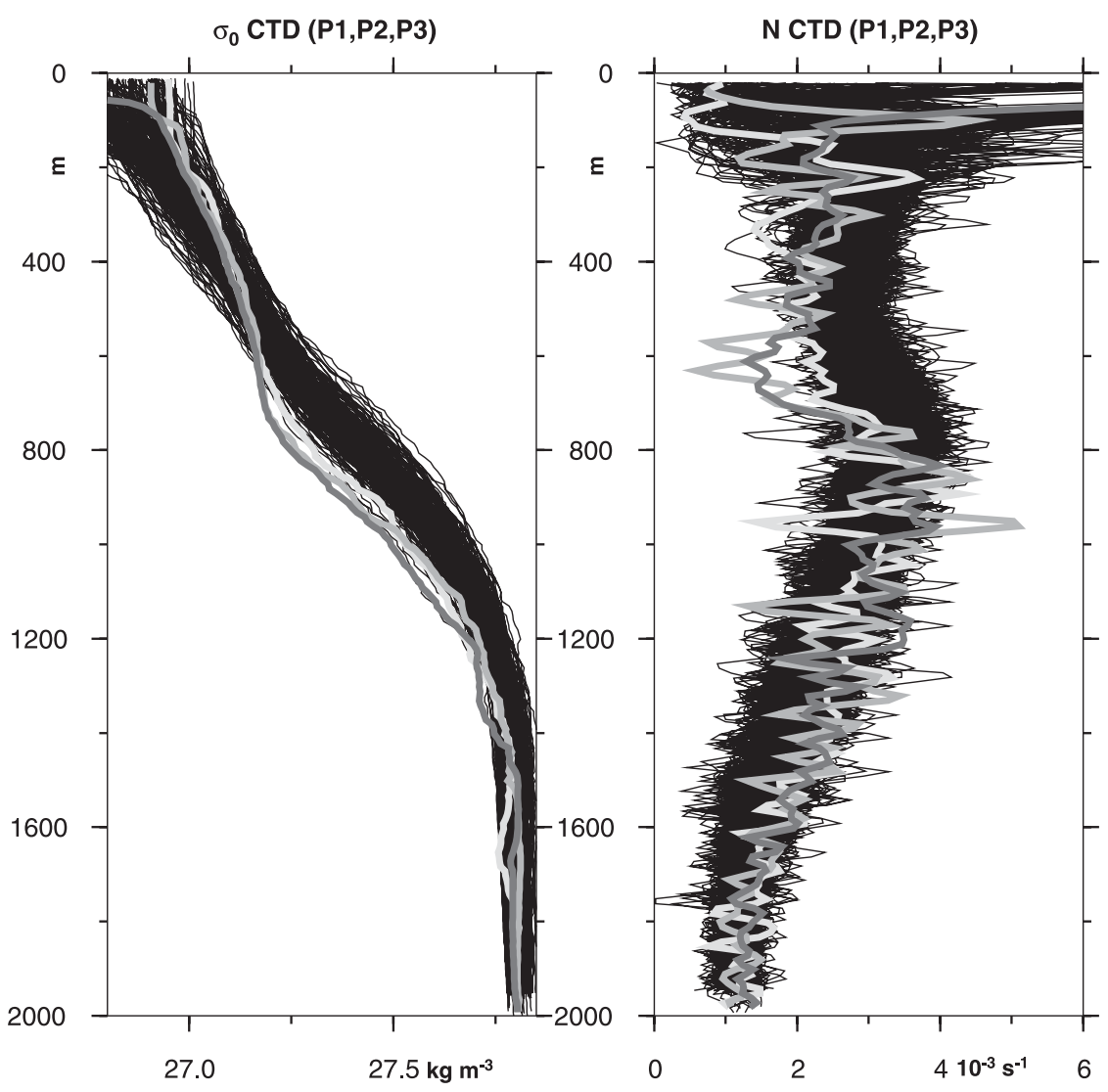

FIG. 6. As in Fig. 5, but for the vertical profiles of $\sigma_{0}$ and Brunt-Väisälä frequency $N$.

indicated similarly large velocities. Both drifters respond to the wind: a velocity response $30^{\circ}$ to the right of the wind for the Marisonde, which is not drogued but has a $100-\mathrm{m}$-long tether in the water, and $90^{\circ}$ to the right of the wind for the Carioca drifter drogued at $15 \mathrm{~m}$ (Assenbaum and Reverdin 2005). During this periodexcept on day 64 (strong wind from the south) - the average wind (or wind stress) was from the east, which could explain the shift of the trajectories with respect to the eddy center (to the northeast for the Marisonde and to the north for the Carioca). The two drifters indicate that at least in the winter season, the SCV has a surface expression. Interestingly, both drifters get expelled from this vicinity on day 65 following the large southerly winds, showing clearly the influence of Ekman currents generated by the winds on the surface layer. Furthermore, shallow subsurface drifter VCM $65(100 \mathrm{~m})$, which approaches to $15 \mathrm{~km}$ of the eddy core center on day 60 and is embedded in the surface mixed layer at that time, did not get trapped in the eddy core circulation, again suggesting a partial decoupling of the surface layer from the core circulation.

\section{e. Velocity vertical structure below the core depth}

The shear between $350-400$ and $950-1000 \mathrm{~m}$ can be estimated from mooring NE, which was twice within the SCV core (at roughly $10 \mathrm{~km}$ from the center by midFebruary and early August 2001; see Fig. 1 for locations of the moorings). At $350-400 \mathrm{~m}$, the velocity averaged $17 \mathrm{~cm} \mathrm{~s}^{-1} 10-15 \mathrm{~km}$ from center, whereas at $950-1000 \mathrm{~m}$, it is closer to $6 \mathrm{~cm} \mathrm{~s}^{-1}$, indicative of a strong vertical shear. Notice, however, that the upper estimate is large compared to the float estimates, maybe a result of the different periods sampled (albeit the difference does not disappear when the float data are only taken for the periods for which the mooring was in the SCV core).

Additional information is provided by LADCP profiles. These are bin averaged as a function of distance to the center for the three stations of the leg 1 cruises within the SCV core as well as for some stations a little outside the core during the leg 2 cruises. These profiles (Fig. 10) consistently indicate that the azimuthal current increases from the surface to roughly $500-700 \mathrm{~m}$, as expected. However, the three leg 1 profiles present intense oscillations farther down until $1250 \mathrm{~m}$, so that 

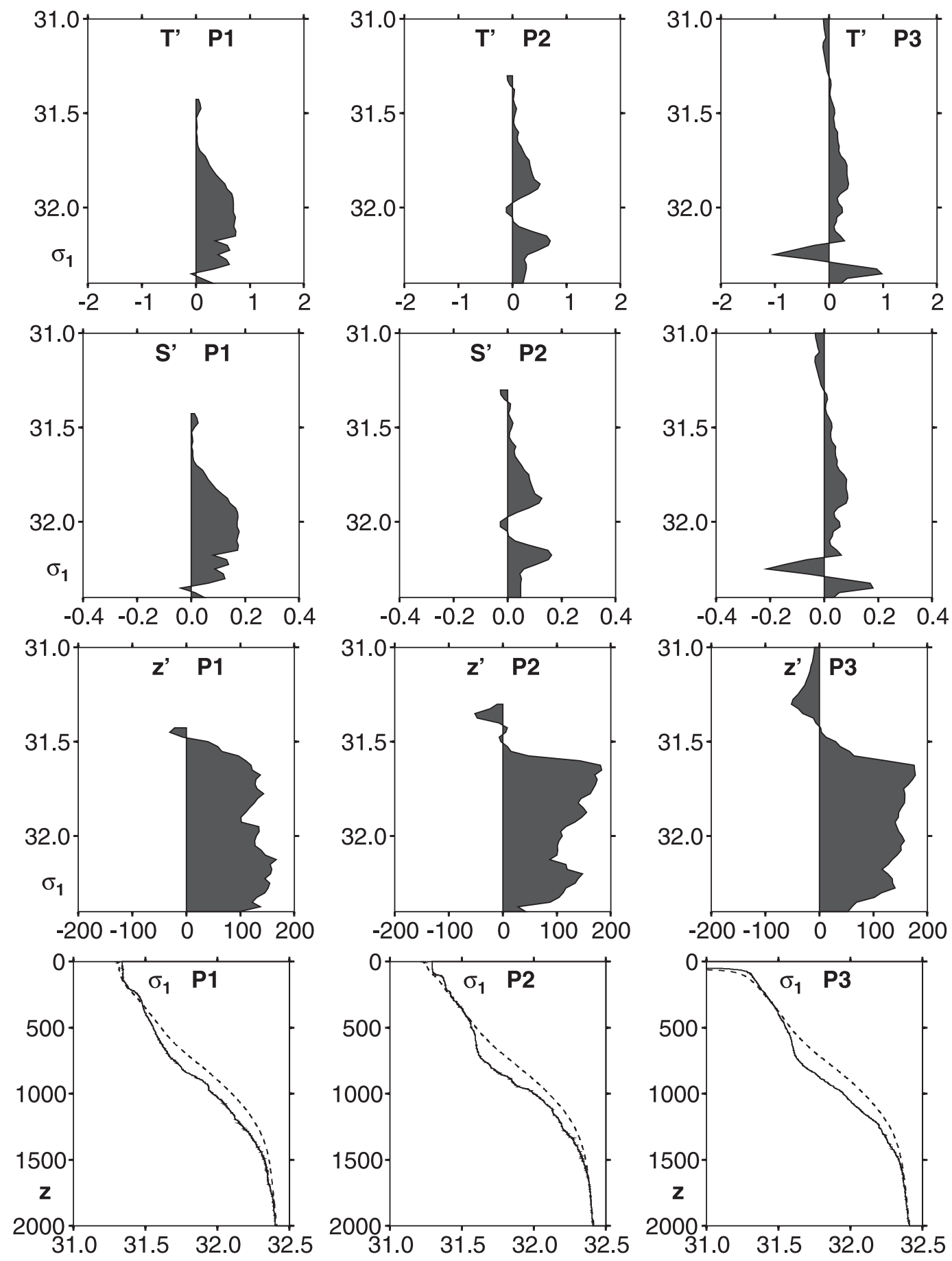

FIG. 7. Temperature, salinity, and depth anomalies of isopycnals in a $\sigma_{1}$ (potential density referred to $1000 \mathrm{dbar}$ ) coordinate for stations in the core. The anomalies are estimated with respect to an average profile (in $\sigma_{1}$ coordinates) of all stations in the POMME domain within $200 \mathrm{~km}$ north or south of the eddy core. (bottom) The $\sigma_{1}$ profiles of the core station (solid line) relative to mean profile of nearby stations (dashed line) as a function of depth.

their average is not significant. They are most pronounced for station $41(\mathrm{P} 2)$, which is closest to the core and where the profile suggests anticyclonic rotation of the current with depth below $800 \mathrm{~m}$ (one complete ro- tation in $300 \mathrm{~m}$ and currents still larger than $15 \mathrm{~cm} \mathrm{~s}^{-1}$ at 1000-1200 m; not shown). This is not seen in any of the LADCP profiles farther away (mostly near $40-50 \mathrm{~km}$ ) from the center. 


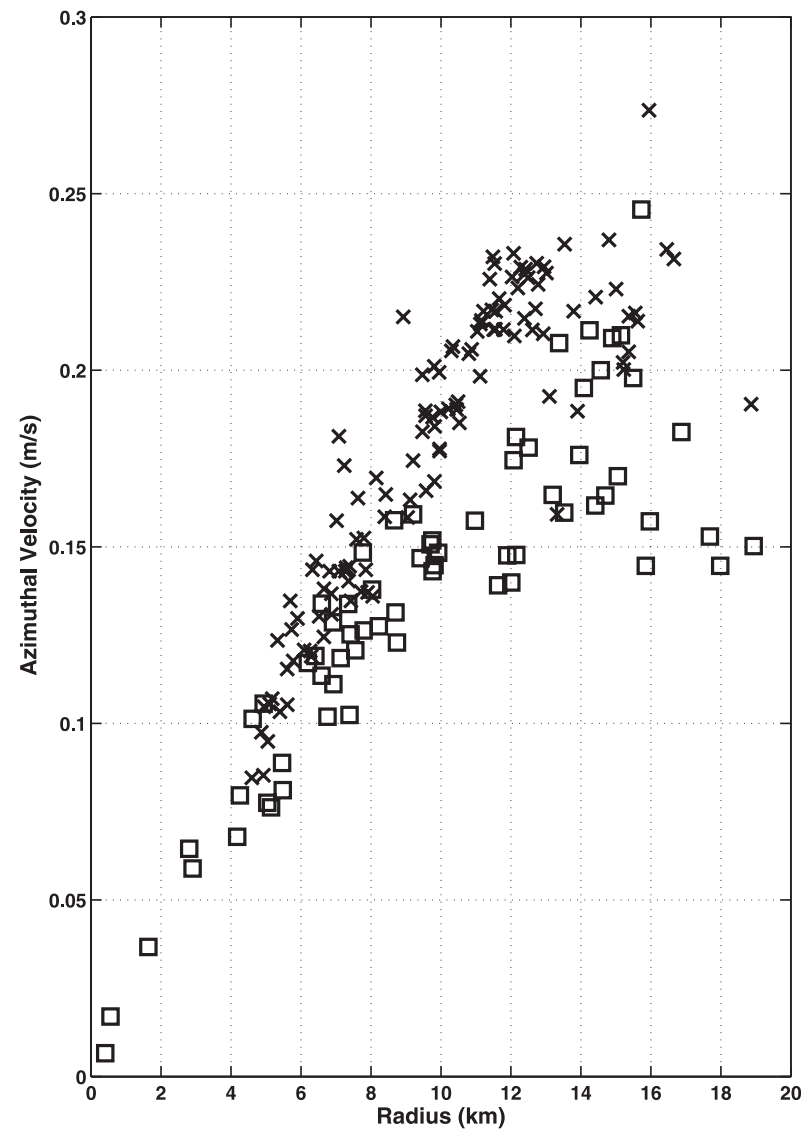

FIG. 8. Azimuthal velocities as a function of radius to SCV center for MV 19954 (crosses) and VCM RAFOS 30 (squares). One velocity estimate is provided by half rotation period around the center (center positions are estimated independently for the two floats).

The strong vertical shears at a relatively short vertical scale seen in individual LADCP profiles close to the core suggest large high-frequency variability in those layers. Indeed, near-inertial oscillations dominate the NE mooring current records at $950 \mathrm{~m}$ when it is within $20 \mathrm{~km}$ of the eddy center (Fig. 11). The period estimated from the mooring records is on the order of $17 \mathrm{~h}$, with large uncertainty because the oscillations are large, the mooring position moves considerably with respect to the core center in a few periods, and the total duration of measurements close to the center is only on the order of 30 days. The azimuthal velocity indicates that the average circulation is still anticyclonic at $950 \mathrm{~m}$, such that the actual inertial effective period (frequency $f+\zeta / 2$ ) is close to $19 \mathrm{~h}$. This implies that the dominant period of the motions is clearly subinertial and that the waves could still propagate slightly farther down without been critical. The 8-h position data of SV 108 (not shown) near $1050 \mathrm{~m}$ also indicate very large fluctuations of the velocity, at least around days 75,78 , and 81 , which correspond to the crossing by the float of the location of the SCV core. In addition, there are indications of vertical displacements of this float by up to $8 \mathrm{~m}$ between successive fixes, and if one interprets the reported temperature variability to be vertical displacements of isotherms relative to the float in an average vertical temperature gradient and add it to the float vertical displacement (the two are positively correlated), isotherm displacements can be larger than $20 \mathrm{~m}$ in $8 \mathrm{~h}$, which is indicative of large internal wave energy.

At $10 \mathrm{~km}$ from the center, the amplitude of the oscillations is much larger than the average azimuthal velocity at $950 \mathrm{~m}$ but is comparable to azimuthal velocity observed at the upper level near $350 \mathrm{~m}$ (Fig. 11). At $950 \mathrm{~m}$, the mooring data show a sharp decrease of the amplitude of quasi-inertial motions as distance from the core increases to $30 \mathrm{~km}$. At $350 \mathrm{~m}$, on the other hand, the near-inertial fluctuations of velocity are much smaller and present no dependence to distance from the SCV center.

\section{The mesoscale eddy}

The full horizontal scale of the region with anticyclonic rotation is by far not restricted to the SCV core described in the previous section. All floats that passed within $60-100 \mathrm{~km}$ of the SCV core between January and September 2001 (list reported in section 2a) have shown some anticyclonic rotation. For example, Fig. 12 presents one such 10-day trajectory piece of the 140-m-deep VCM 019, which circled the SCV center defined by float VCM 030 from mid-June until mid-August 2001 at distances varying from 60 to $80 \mathrm{~km}$. This is the longest time a float above the thermocline remained trapped in this anticyclone at this distance from its center. This contrasts with the two floats in the SCV as well as the deeper RAFOS 108 at $1050 \mathrm{~m}$, which remained within the eddy for more than 9 months.

The float and the mooring data suggest a large mesoscale anticyclonic eddy (A1). These data are combined to provide a mean profile of azimuthal velocity across the eddy from January to September 2001 (Fig. 13), assuming that its center coincides with a smoothed version of the SCV center position time series (cf. discussion section). At different upper levels, there is a broad area with positive azimuthal velocities reaching $100 \mathrm{~km}$ from the center. This is found both above the thermocline $(120-430 \mathrm{~m})$ and deeper at 950 or $1050 \mathrm{~m}$. To get a reliable radial profile of the azimuthal velocity, we average the profiles from different levels in two depth ranges. These profiles show a maximum velocity near $50-60-\mathrm{km}$ radius for the upper average (120-430-m depth) rather than for the lower average (950-1030-m 
Marisonde 15501 (days 43-64)

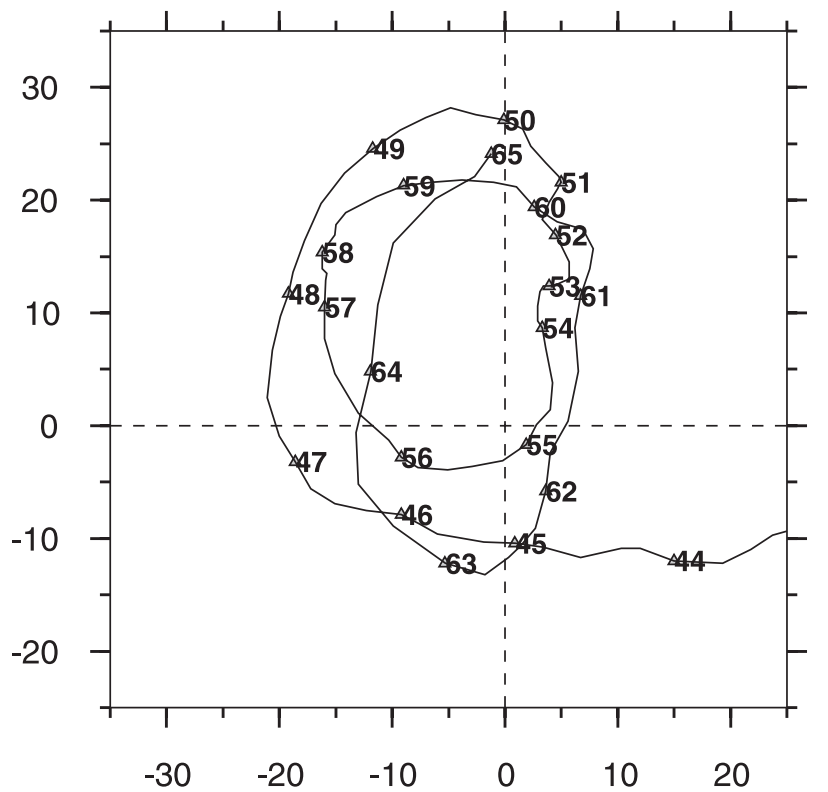

Carioca 01110 (days 43-64)

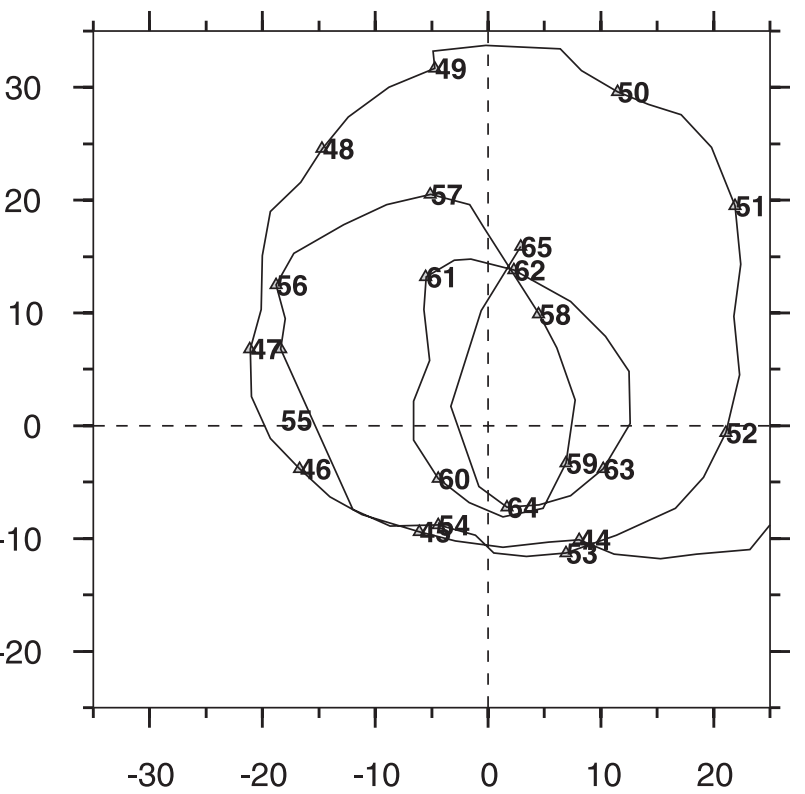

FIG. 9. Trajectories in February and early March of two surface drifters (Marisonde 15501 and Carioca 01110) in relative position to the SCV center (based on Surdrift 24331 GPS position data). The 2001 calendar day is reported at the float position at the beginning of each day.

depth), with a noticeable decrease at larger distances, which could imply a change of sign of relative vorticity (Fig. 13). Interestingly, maximum velocities at $480 \mathrm{~m}$ are noticeably higher in the SCV, suggesting that the mesoscale velocity/vorticity structure is somewhat disconnected from the SCV.

This large scale of the mesoscale eddy is confirmed by (a) geopotential anomalies (GPAs) at 300-m depth referred to $2000 \mathrm{~m}$ (not shown) and (b) sea level anomalies (SLAs) calculated from satellite altimeters, as shown in Fig. 12. The amplitude of SLAs typical of A1 amounted commonly to $10 \mathrm{~cm}$ with respect to values at a distance of $100 \mathrm{~km}$, which is consistent with GPAs found to average $1.0 \mathrm{~m}^{2} \mathrm{~s}^{-2}$ at 0 - or $300-\mathrm{m}$ depth. Assuming a cyclostrophic balance, the current profile from the upper average of Fig. 13 can be integrated to estimate a GPA at the center. We find $1.4 \mathrm{~m}^{2} \mathrm{~s}^{-2}$ for GPAs at the center relative to a radius of $100 \mathrm{~km}$ and $1.03 \mathrm{~m}^{2} \mathrm{~s}^{-2}$ relative to a radius of $60 \mathrm{~km}$. This is of a similar magnitude or a little larger than the observed GPAs of the hydrological surveys or the SLAs from altimetry maps (an underestimate in SLAs is expected from the processing of altimetric data and the mapping used to produce the SLA maps).

The velocity structure based on float and mooring data also indicates that the velocity is $40 \%$ less at 1000 $1100 \mathrm{~m}$ than at $400 \mathrm{~m}$. Thermal wind from the CTD data suggests that azimuthal velocity decreases with depth at least to $1500 \mathrm{~m}$ (Fig. 14), with little shear below that level. Current profile data (Fig. 11) confirm the large shear from 700 to $1500 \mathrm{~m}$ and that there is little shear below that (to $2200 \mathrm{~m}$ ). However, these data indicate that there are still anticyclonic azimuthal velocities reaching on the order of $2 \mathrm{~cm} \mathrm{~s}^{-1}$ between 1500 and 2200 $\mathrm{m}$ (significantly nonzero in the binned averages). Only two profiles reach deeper layers (to at least $3200 \mathrm{~m}$ ), so that we cannot conclude on the deeper portion of the velocity profile and on the velocity near the ocean bottom associated with this eddy. The LADCP data also suggest relatively little shear above $750 \mathrm{~m}$ away from the core, with a possible increase toward the surface in the $40-50-\mathrm{km}$ radius range and some increase between 750 and $400 \mathrm{~m}$ at larger distances, consistent with the float data. This contrasts with the SCV core for which $25 \%$ faster rotation rates appeared for float MV 19954 (1 revolution every 4 days) near 450-500-m depth compared with float VCM 30 (1 revolution every 5 days) near 250-m depth (Fig. 8).

The few floats that were found in this area in late 2000 or early 2001 as well as the altimetric maps indicate that the mesoscale eddy was much weaker then, with no coherent rotation at distances larger than $50 \mathrm{~km}$ from the center. It seems possible that part of the anticyclonic eddy was separated from the core, as is suggested then by the large separation between the core center and the center of the mesoscale altimetric eddy (refer to the 

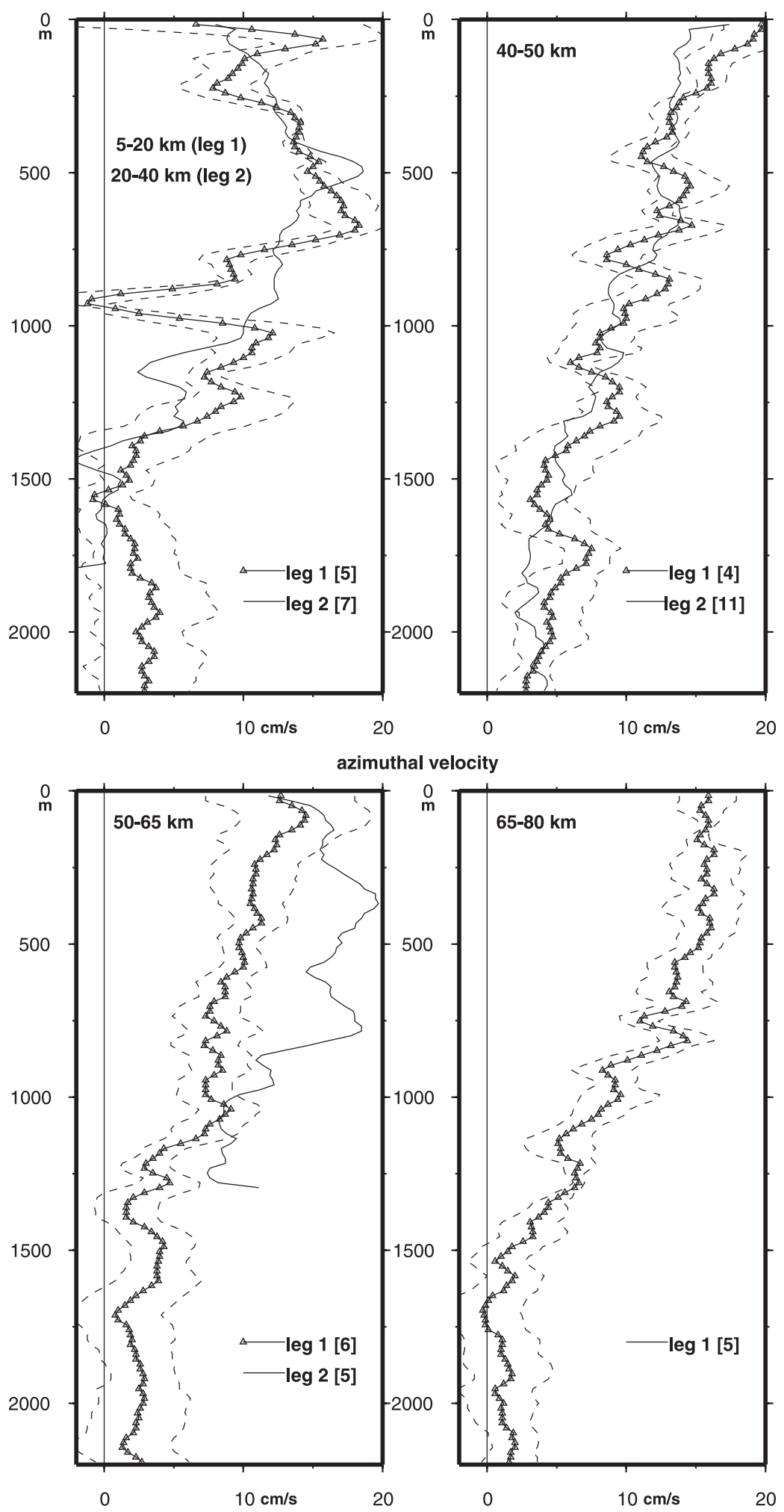

FIG. 10. Average profiles of azimuthal velocity from LADCP profiles as a function of depth for different radius ranges. The leg 1 averages are indicated (triangles) as well as a $2 \sigma$ uncertainty range (dashed curves). The full curve is for the leg 2 average. The number of LADCP stations is indicated in the brackets. 

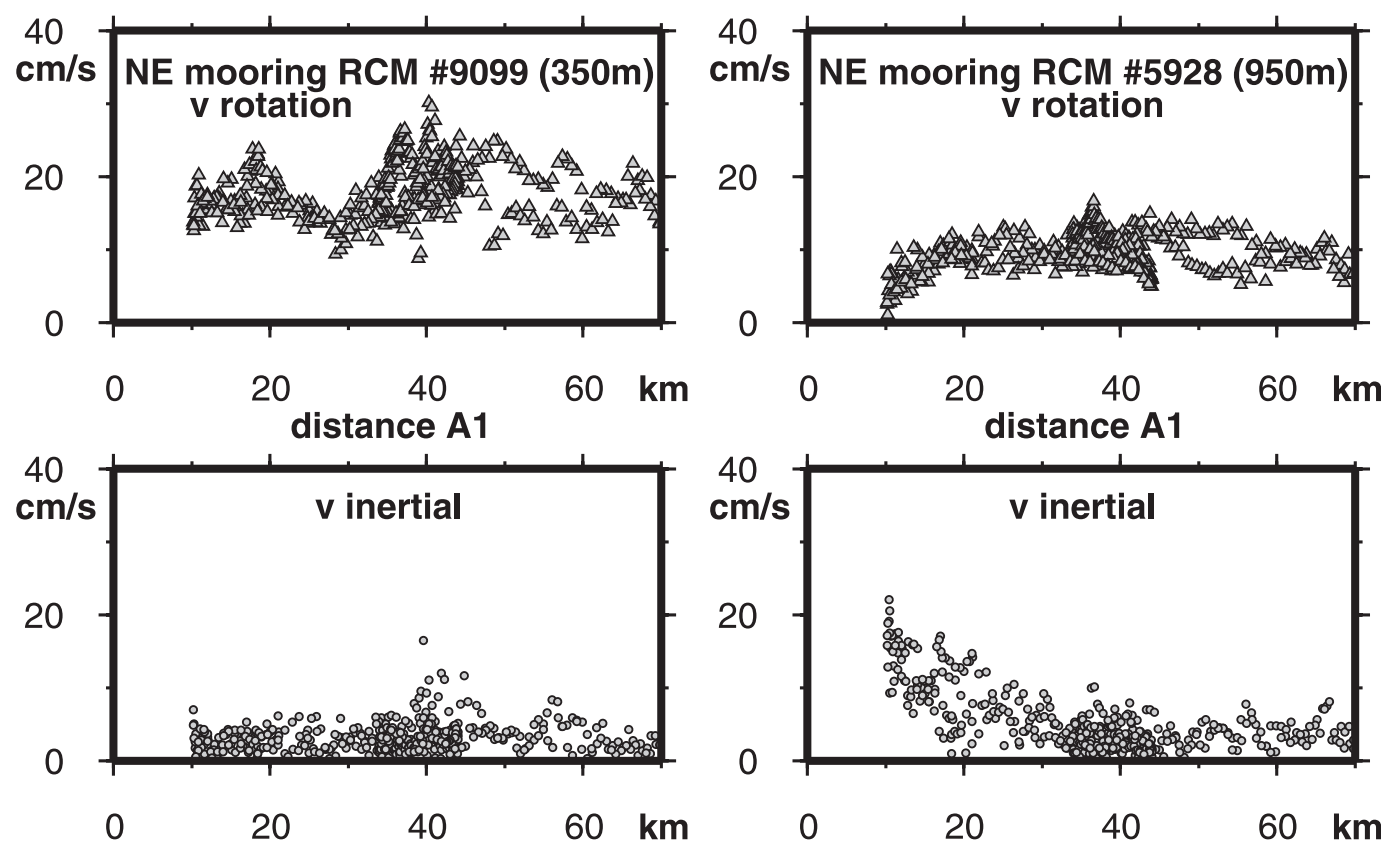

FIG. 11. Estimates every $8 \mathrm{~h}$ of (bottom) near-inertial velocity amplitude and (top) averaged azimuthal velocity (upper panels) as a function of distance to eddy center from 2 current meters on northeast mooring (left, $350 \mathrm{~m}$; right, $950 \mathrm{~m}$ ). The hourly velocities are first calculated relative to a moving referential origin: for distances less than 20-25 km, this is the position of the SCV center; for larger distances, the smoothed eddy center position is retained (Fig. A1). Over 17-h time series segments, the relative velocities are fitted to the sum of a mean and an inertial oscillation to estimate a near-inertial velocity amplitude. The mean is then decomposed in azimuthal and radial velocity components.

appendix). It gained in strength and coherence by midJanuary, maybe by coalescence of two anticylonic eddies (Le Cann et al. 2005).

\section{Discussion}

We have illustrated from the velocity data two rather different structures: a SCV and a larger mesoscale eddy embedding the SCV. The SCV velocity peaks at $12-15$ $\mathrm{km}$ from its center, whereas the velocity in the larger mesoscale eddy peaks near 50-60 km from its center. The SCV presents a subsurface velocity maximum near 600-650-m depth and is not clearly present at $1000 \mathrm{~m}$, whereas the mesoscale eddy is reinforced toward the surface but extends to at least $1500 \mathrm{~m}$. Furthermore, the mesoscale eddy does not trap water masses, contrary to the SCV core. We will now discuss remaining questions on the SCV steadiness and structure, its relation with the mesoscale eddy, the interactions with the bathymetry (the shallow segment of the Azores-Biscay ridge), and what we can tell of the origin of the SCV.

\section{a. The SCV}

At its core, the SCV has a relative vorticity close to $-f / 2$ (at $450-500 \mathrm{~m}$ ), is highly nonlinear (Rossby numbers are expressed as $R=\xi / f$, which varies from an absolute maximum of 0.5 at the eddy center to $R_{0}=0.125$, where the azimuthal velocity presents a maximum at a distance of $13-15 \mathrm{~km}$ ). It has relatively small horizontal $(L=15 \mathrm{~km})$ and vertical $(H=1000 \mathrm{~m})$ extents, with a Burger number defined as $N^{2} / f^{2} H^{2} / L^{2}$ averaging 0.16 over that layer. It is, thus, vertically and horizontally much smaller than mesoscale eddies in this region, and its high nonlinearity should protect it from too large interaction with the mesoscale environment. It might, however, be strained by shear in the large-scale mesoscale eddy (Lilly and Gascard 2006).

The SCV azimuthal velocity structure seems rather stable through the 11 months of its sampling (no indication from the two floats trapped in it of a reduction of velocity in time). Its inner core remained well preserved from mixing with its surrounding. The transition layer around it, which includes the velocity maximum and presents horizontal gradients in water mass properties (Figs. 2, 3) and vorticity, is, however, indicative of erosion of this core, possibly by horizontal mixing/stirring, although we cannot quantify the time scales associated with it.

The large near-inertial and internal oscillations witnessed below its core could be indicative of trapped 


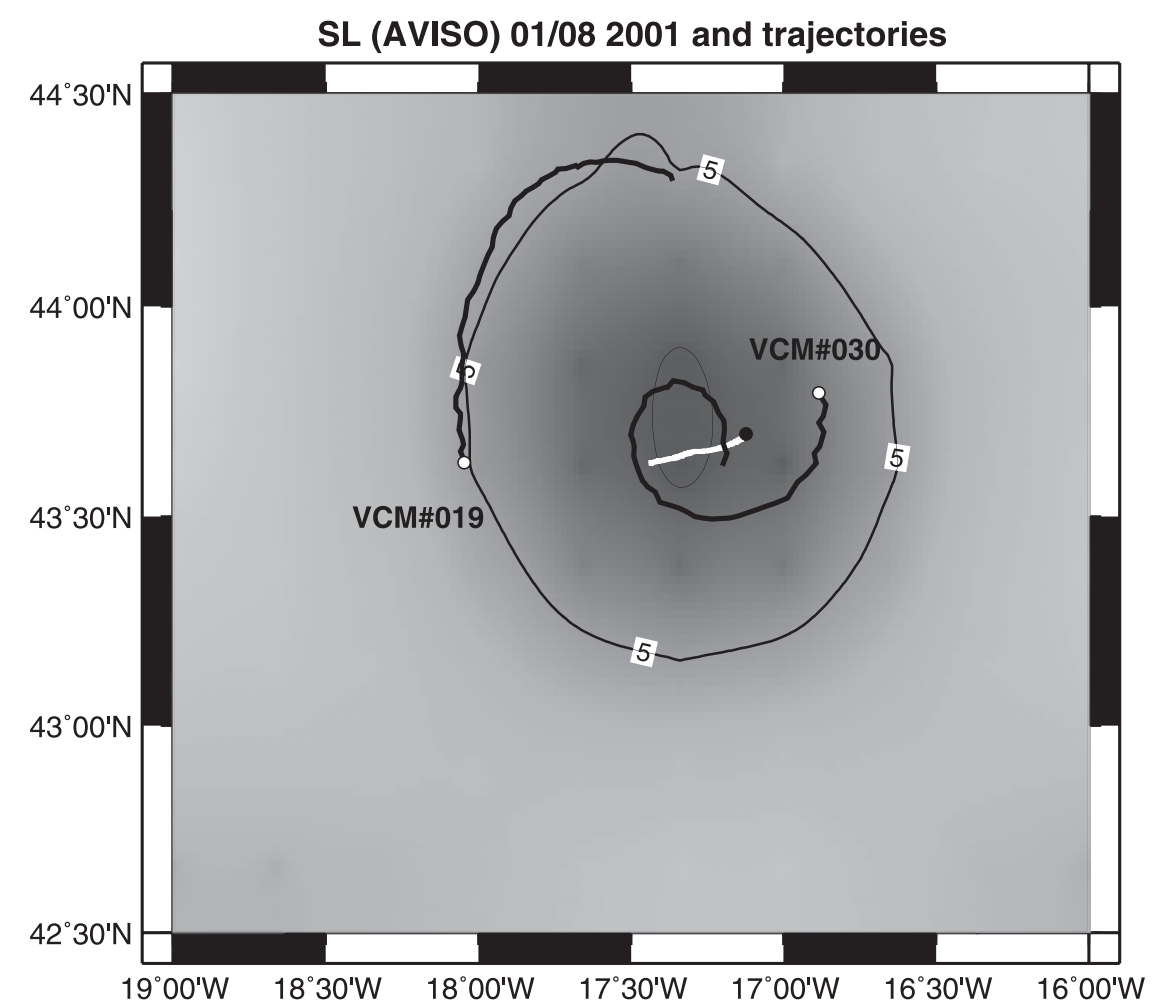

FIG. 12. Sea level $(\mathrm{cm})$ from satellite altimetry (AVISO product) over eddy A1 on 1 Aug 2001 (contours 0,5 , and $10 \mathrm{~cm}$ ). Here, 10-day portions of the SCV center trajectory (white) as well as floats VCM 030 and VCM 019 (black). Dots plotted at beginning of each trajectory.

waves. The anticyclonic rotation with the depth of the current witnessed on station 41 (P2) LADCP data (and the upward displacement of the velocity profile between down- and upcasts of that station; not shown) is indicative of downward energy flux. The increase of amplitude of these oscillations with depth (to maximum velocities near 1000-1200 m) suggests a decrease in wave group velocity toward that depth. We have also found (in RAFOS 108 and current meter data) evidence for large near-inertial variability near $950-1050 \mathrm{~m}$. Although we do not have enough data to quantify these energy fluxes, these observations are coherent with studies on internal waves trapped in intense anticyclonic eddies (Kunze et al. 1995; Kunze 1986), which emphasize the presence of near-critical layers below the core. Interestingly, we do not find an increase of near-inertial energy above the core compared to the surrounding domain-both in floats and current meter data-and, therefore, no particular horizontal trapping of nearinertial energy at those depths. A similar suggestion was made for a shallower subtropical mode water eddy by Pingree (1996).

This large near-inertial variability below the SCV is associated with large vertical shear of horizontal velocity. It is possible that these are associated at times with shear- induced mixing, as is suggested from station 41 of $\mathrm{P} 2$, with gradient Richardson numbers ( $\mathrm{Ri}$ ) estimated from the $16 \mathrm{~m}$ binned current data lower than 0.4 for the depth ranges $870-930$ and $1100-1150 \mathrm{~m}$ [in the upper layer, despite significant stratification on that vertical scale $\left.\left(N^{2}=0.710^{-5} \mathrm{~s}^{-2}\right)\right]$. These regions of low Ri also present finer-scale well-homogenized layers (4-8 $\mathrm{m}$ thick) that could have resulted from mixing events. No other station from the POMME surveys has such low Richardson numbers in this stratified thermocline layer, but no station was visited as close to the SCV center.

\section{b. Relation of the SCV to the mesoscale eddy}

The high negative relative vorticity in the SCV core is quite similar to values reported in the literature (Le Groupe Tourbillon 1983) for the "Tourbillon" eddy observed in 1979 in the northeast Atlantic at about $47^{\circ} \mathrm{N}$ and $15^{\circ} \mathrm{W}$ and also for other eddies (swoddies) in the Bay of Biscay $\left(44^{\circ}-45^{\circ} \mathrm{N}\right)$, such as F90a and X91 reported by Pingree and Le Cann (1992). In contrast to the SCV, the mesoscale eddy is in constant interaction with the environment, with implications on its evolution. This is witnessed by the floats that continuously penetrate or leave the eddy from other current structures (for example, the rim current of cyclonic eddy $\mathrm{C} 4$; 


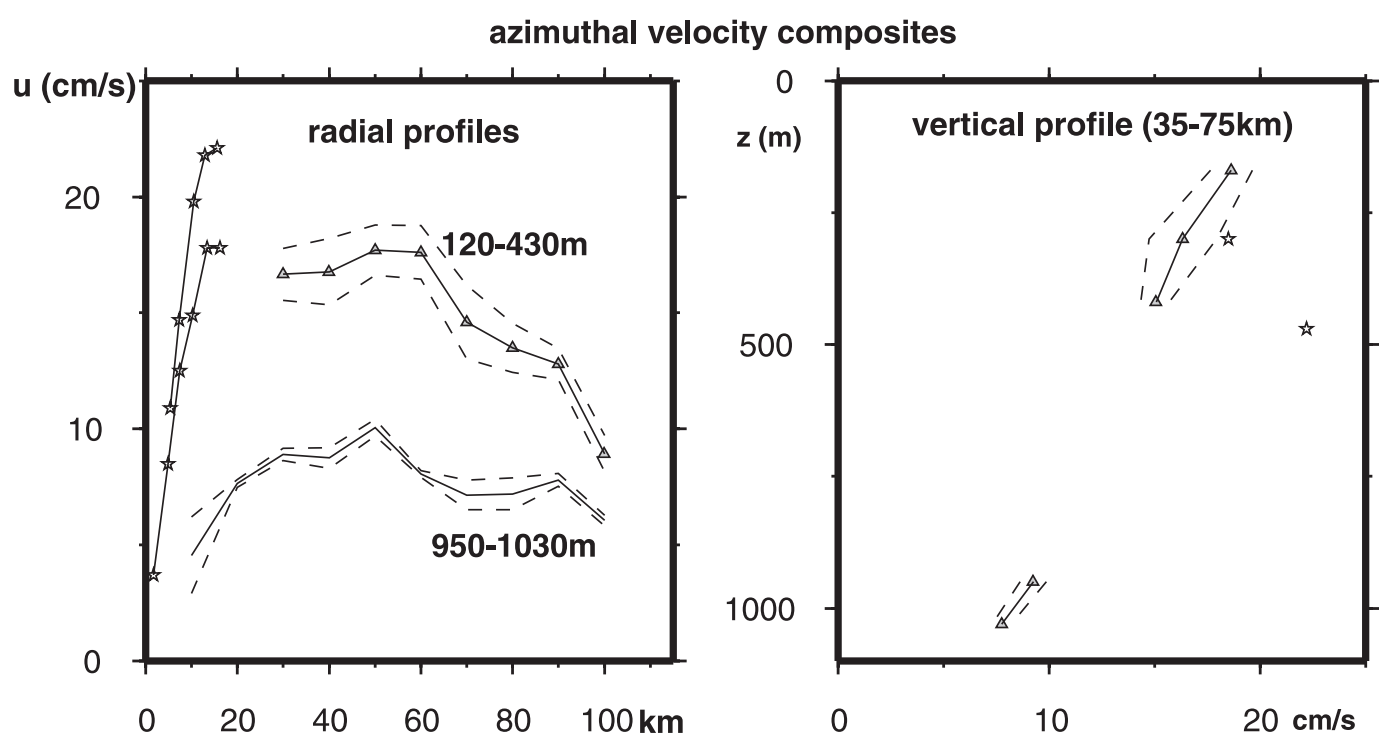

FIG. 13. Azimuthal velocity as a function of distance to eddy (left) center or (right) depth. All velocity data from the floats and from the current meters within the eddy have been included, except for the two floats within the SCV (MV 19954 near 450-500 m and VCM 030 near 250-300 m), which are treated separately (stars; right corresponds to maxima of left). First, azimuthal velocity relative to the smoothed eddy center position (see Fig. A1) is estimated. Then, the inertial and high-frequency oscillations are filtered out, and resulting velocities are averaged in 10-km radius bins and in depth ranges. Profiles are continuous from at least $35 \mathrm{~km}$ for data in 5 depth ranges: one between 120 and $2020 \mathrm{~m}$, the others near 300, 420, 950, and $1030 \mathrm{~m}$. (left) The three upper profiles (two lower profiles) are averaged together (solid line), and an error on this average ( $2 \sigma$ range between the dashed lines) is estimated based on the deviations with respect to the average profile normalized by a vertical dependency (see right panel). (right) An average depth profile by averaging bins between $35-$ and $75-\mathrm{km}$ radius range [an error on this average is estimated based on the deviation of individual radius bins from an average profile (from left panel); $2 \sigma$ range between the dashed lines].

Le Cann et al. 2005). The outer structure shape depicted by the floats or altimetry also evolves considerably in time.

The anticyclonic looping trajectory of the SCV core (Fig. 1) might indicate that it is actually not located at the mesoscale eddy center but that it is somewhat advected by the eddy circulation at a distance from its center (from December through late April). Any displacement of the SCV center from the mesoscale eddy center would then result in an anticyclonic looping of the SCV center.

During days 83-106, the velocity displacement of the core is usually larger than $6 \mathrm{~cm} \mathrm{~s}^{-1}$ (and for 12 days, it is larger than $\left.8 \mathrm{~cm} \mathrm{~s}^{-1}\right)$. These velocities are much larger than the $O\left(2-3 \mathrm{~cm} \mathrm{~s}^{-1}\right)$ displacement velocities typical of anticyclonic eddies during POMME (Le Cann et al. 2005) and are much larger than expected self-propagation velocities of coherent SCVs (Mc Williams and Flierl 1979). During that period, velocity data of moorings NE (near 350) and NW (near $400 \mathrm{~m}$ ) located outside the SCV core also support a separation between the SCV core and mesoscale eddy center. They indicate more regular azimuthal velocities (not shown) when they are estimated with respect to a smoothed version of the eddy center position (refer to the appendix) than with respect to the SCV core position. On the other hand, adopting the smoothed center trajectory still leaves large radial velocities on NE's record (up to $20 \mathrm{~cm} \mathrm{~s}^{-1}$ on day 95 that is oriented parallel to the Azores-Biscay ridge), possibly an indication of a strong deformation of the eddy at that time. A difference in displacement velocity of the eddy and of the SCV core is also evident on the 30 April S-ADCP section (Fig. 3). At that date, the core center is moving southwest at $4 \mathrm{~cm} \mathrm{~s}^{-1}$ according to the floats. In the core the zonal velocity profile is shifted by $-4 \mathrm{~cm} \mathrm{~s}^{-1}$, as is expected for a translating SCV, whereas outside the core, zonal velocities have roughly opposite values on both sides, suggesting very little zonal translation of the mesoscale eddy.

At times, the looping velocities are weaker than the mesoscale eddy velocity we expect at these distances $(10-40 \mathrm{~km})$ from the center of the mesoscale eddy (Fig. 13), so that the SCV does not just drift "advected" by the mesoscale eddy velocity. Furthermore, Lilly and Gascard (2006) suggest that the SCV core is an ellipse resulting from the strain deformation of a circular vortex. The strain could result from the mesoscale eddy if its center does not coincide with the SCV center. 
Geopotential anomalies (P1,P2,P3)

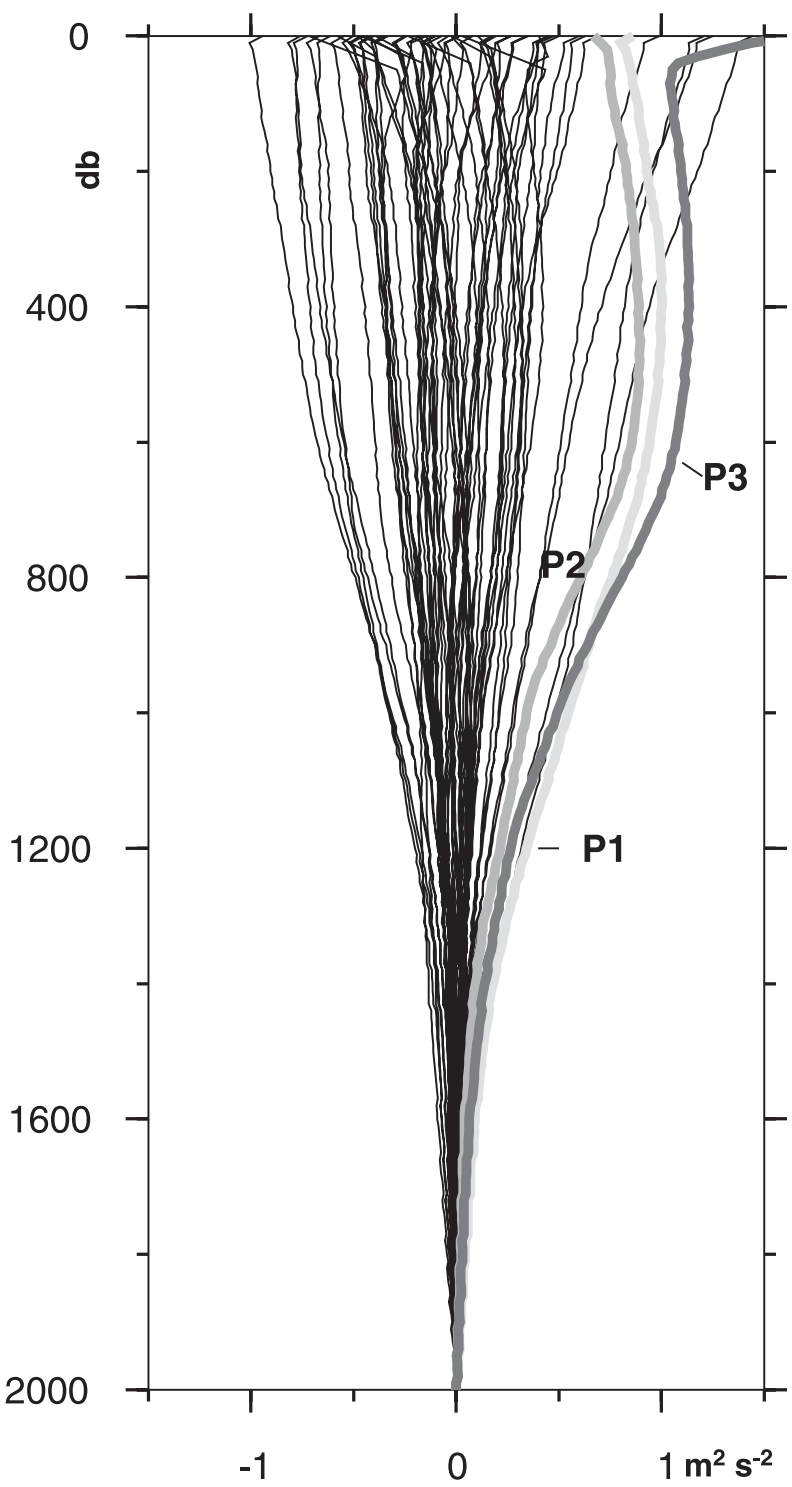

FIG. 14. Vertical profiles of GPA relative to 2000 dbar calculated from all the CTD casts of P1 leg 1 (R/V Atalante) are represented (solid lines) and overlaid with the core profiles (thick line) for P1 CTD cast 23 (light gray), P2 CTD cast 41 (gray) and P3 CTD cast 26 (dark gray).

\section{c. Interaction with bathymetry}

One of the striking features of eddy A1 is the weak mean horizontal displacement from mid-December 2000 until early September 2001 associated with this eddy (Fig. 1 and the appendix), in contrast with the general behavior of most of the other mesoscale eddies observed in the POMME domain over the whole year, which drifted to the west or southwest (Le Cann et al. 2005). This suggests trapping by the shallow segment of the Azores-Biscay ridge found there. A similar trapping situation was pointed out by Paillet et al. (2002) for a meddy observed above Charcot seamounts- $500 \mathrm{~km}$ to the west-northwest of eddy A1 position-but no conclusion could be reached on the surprising steadiness of this meddy over a long period of time. In the case of A1, the general anticyclonic displacement of the eddy center around the bathymetric shallow features of the Azores-Biscay Rise is better characterized, suggesting a weak bathymetric beta-effect.

There is also a suggestion of elongation of the eddy parallel to bathymetry. For example, VCM 19 during its three circumvolutions of A1 (Fig. 15) presents an elongated (ellipsoid) trajectory with its long axis rotating anticyclonically in time $\left(150^{\circ}\right.$ in 60 days), whereas the eddy center drifts anticyclonically around the high rise of the Azores-Biscay ridge. Such ellipsoid trajectories and their rotation in time are, however, observed in other mesoscale eddies, as for some STORM eddies for which it is not related to the interaction with bathymetry (Pingree and Sinha 1998).

The few velocity measurements below $2000 \mathrm{~m}$ during POMME in this area (LADCP profiles) indicate flows typically of $2 \mathrm{~cm} \mathrm{~s}^{-1}$, which could induce a weak interaction of the vorticity field of the eddy with the bathymetry. However, as the eddy is reinforced in the upper thermocline far from the bottom, the effect of this interaction on the eddy would be very difficult to establish. Whether it involves or not the interaction with cyclones formed by potential vorticity conservation when an anticyclone approaches the topography, as in the study of loop current eddies along the continental slope of the Gulf of Mexico (Frolov et al. 2004), is difficult to ascertain. It is also possible that the interaction with bathymetry could have resulted in the merging of two anticyclones, as indicated in Le Cann et al. (2005) in early 2001, and the separation of the SCV from the mesoscale eddy center, resulting in its looping behavior. A compilation of all available float trajectories also indicated that this ridge has an effect on the large-scale circulation at intermediate depths (Bower et al. 2002).

\section{d. Origin of the SCV}

The high negative relative vorticity in the SCV core is quite similar to values reported for the Tourbillon eddy observed in 1979 in the northeast Atlantic at about $47^{\circ} \mathrm{N}$ and $15^{\circ} \mathrm{W}-200$ miles from A1 (Le Groupe Tourbillon 1983) — and also for other eddies (swoddies) observed further southeast in the Bay of Biscay, such as F90a and X91, reported by Pingree and Le Cann (1992). The Tourbillon eddy was characterized by an inner core also made of northeast Atlantic central mode waters. This-together with typical anticyclonic eddy trajectories (Le Cann et al. 2005)-leads us to speculate about the 


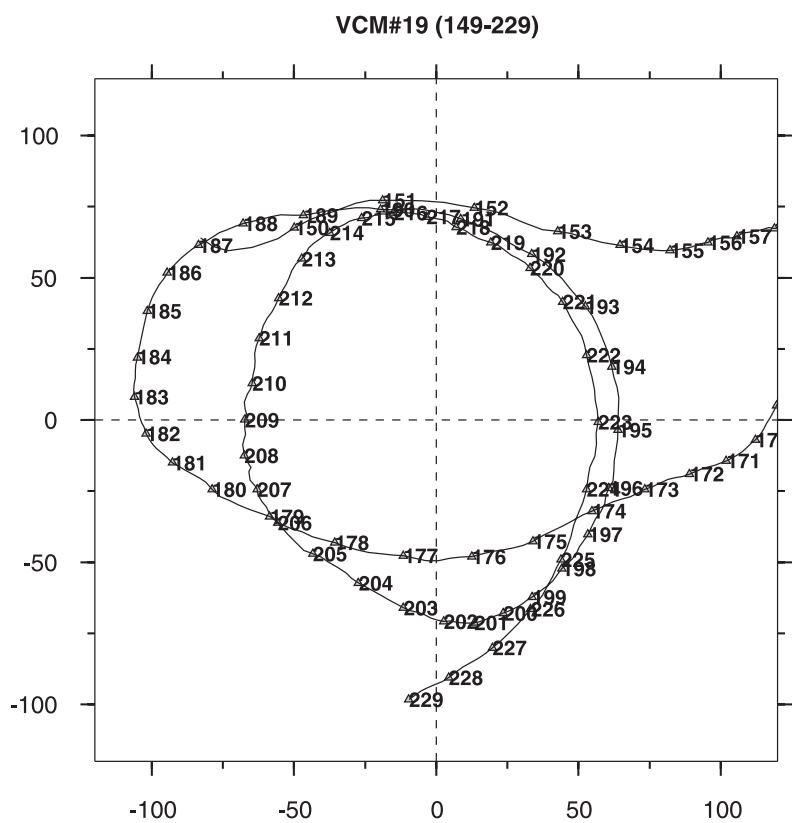

FIG. 15. Two-month trajectories for float VCM 19 in relative positions to smoothed eddy center position (Fig. A1). During that time (2001 calendar days 149-229), the eddy center turns anticyclonically around $44^{\circ} \mathrm{N}, 17.5^{\circ} \mathrm{W}$ (Fig. 1). The calendar day is reported at the float position at the beginning of each day.

most probable area of formation for the SCV, which is to the northeast of the POMME area. The mode water characterizing the core of A1 SCV is significantly warmer and saltier than the core of the Tourbillon eddy. Where was that water in contact with the sea surface? The climatological fields would indicate an area midway between $\mathrm{A} 1\left(43^{\circ}-44^{\circ} \mathrm{N}\right)$ and Tourbillon $\left(47^{\circ} \mathrm{N}\right)$, or possibly further eastward toward the southern Bay of Biscay. However, interannual variability has been reported in this region with large recent temperature and salinity increases. The available surface data (in 1999-2000; Reverdin et al. 2007) suggest that the formation region of the water mass in the A1 SCV's core is north of $47^{\circ} \mathrm{N}$, possibly along the shelf breaks of the northern Bay of Biscay near Goban Spur $\left(49^{\circ} \mathrm{N}\right.$, $\left.12^{\circ} \mathrm{W}\right)$, a region where the winter mixed layers are known to often reach $500 \mathrm{~m}$ (as seen, for example, in recent ocean glider data or in historical XBT data (de Boyer Montégut et al. 2004), a depth that could be larger if contained within an anticyclone.

Altimetric sea level observations were only able to track a mesoscale eddy back to 28 June 2000, when it was close to $44.5^{\circ} \mathrm{N}, 14^{\circ} \mathrm{W}$. Assuming that the SCV was in this eddy, the characteristic meridional displacement velocity $\left(1-2 \mathrm{~cm} \mathrm{~s}^{-1}\right)$ makes it unlikely that the SCV was north of $47^{\circ} \mathrm{N}$ in late winter 2000 . Also, the complicated upper structure depicted from the high-resolution
CTD section (Fig. 2) suggests a formation in the previous year, a remnant of 2000 mode water being possibly at intermediate depths near 350-400 m.

Assuming a formation in 1999, the local maximum of oxygen values in the weakly stratified core can be used to estimate an upper bound of oxygen consumption since formation as $7.5 \mu \mathrm{mol} \mathrm{kg}{ }^{-1} \mathrm{yr}^{-1}$, assuming saturation at formation and no mixing with surrounding water (which would contribute to a lowering of the oxygen value). This rate is also compatible with the difference between stations 26 of P3 and 41 of P2 dissolved oxygen profiles, although this is less reliable as the two stations were not at the same distance from eddy center. This is somewhat lower than van Aken's (2001) estimate for the density range $\left(9.6 \mu \mathrm{mol} \mathrm{kg}{ }^{-1} \mathrm{yr}^{-1}\right)$, a difference that could be due to the rather deep level of this water and that we are at the denser end of the range in van Aken's paper. The value is also compatible with the estimates of mineralization done during POMME (Fernández et al. 2005b; Maixandeau et al. 2005), which tend to be rather low (below $500 \mathrm{~m}$ ).

We expect SCVs formed at latitudes higher than $47^{\circ} \mathrm{N}$ to present deep layers depleted of Mediterranean water, as was found for the Tourbillon eddy $\left(47^{\circ} \mathrm{N}, 15^{\circ} \mathrm{W}\right)$, which had a rather similar structure in the thermocline-albeit extending, maybe, a little deeper. However, A1 presents an enrichment in this water mass under the core of the SCV - at least until April 2001-whereas for Tourbillon, the enrichment was found as a ring on the outskirt of the eddy. Why should the Mediterranean water masses' influence be greater just underneath the eddy A1? A possibility was that deeper water masses such as Mediterranean water masses would have been entrained by A1 through eddy-eddy interaction for which there is some suggestion early during POMME (Le Cann et al. 2005). The POMME domain was influenced by meddies propagating in the southwest direction (Le Cann et al. 2005). One of the anticyclonic features with Mediterranean water signature that could have later been incorporated in A1 was observed during the September 2000 hydrographic survey in the area. In any case, we observed little trapping of water at those depth under the SCV core between March and August. Such a vigorous exchange between the core and outer layer is consistent with the evolution seen for float SV 108 at $1050 \mathrm{~m}$. This float left the central region of large $T-S$ anomaly after $\mathrm{P} 2$ in April to the outer layer. It then drifted back close to the center in June with much smaller $T-S$ anomalies.

\section{Conclusions}

During the POMME experiment, we observed a coherent anticyclonic submesoscale vortex (SCV) $30 \mathrm{~km}$ 
in diameter, made of northeast Atlantic central mode waters $\left(T=11^{\circ}-12^{\circ} \mathrm{C}\right.$ and $\left.S=35.5-35.6\right)$ extending down to about $700-\mathrm{m}$ depth. The SCV core is characterized by major anomalies in contrast with the background field as follows: 1) strong anticyclonic vorticity approaching $-0.5 f$ at the very center of the eddy, increasing with depth down to $600 \mathrm{~m}$; 2) a strong positive geopotential anomaly of about $1.0 \mathrm{~m}^{2} \mathrm{~s}^{-2}$ at about $300-\mathrm{m}$ depth (referred to $2000 \mathrm{~m}$ ); 3) a low Brunt-Väisälä frequency near $650 \mathrm{~m}$ (close to $1.010^{-3} \mathrm{~s}^{-1}$ ), characterizing a low-density stratification along the vertical; 4) a very low potential vorticity resulting from 1 ) and 3 ) $\left(\sim 0.510^{-11} \mathrm{~m}^{-1} \mathrm{~s}^{-1}\right)$; and 5) a high level of dissolved oxygen $\left(249.5 \mu \mathrm{mol} \mathrm{kg}{ }^{-1}\right.$, near $93 \%$ of saturation values), suggesting that the water masses characterizing the eddy core were formed during a deep winter mixing event and are more recent than surrounding waters. We can also indicate observations taken during P3, the last POMME cruise in September 2001, indicating a high level of nutrients near the surface related to the uplifting of the upper isopycnal surfaces (Fernández et al. 2005a). There is no indication of an associated local maximum in production during the $\mathrm{P} 3$ survey, contrary to what was witnessed for another mode water eddy in the western subtropical Atlantic by McGillicuddy et al. (2007), albeit the high nutrient values observed in the euphotic zone near A1 during P3 are likely to result in additional production (see also the discussion for a swoddy in Garcia-Soto et al. 2002).

The SCV core isolation from the air-sea surface was close to $1.5 \mathrm{yr}$ at the beginning of POMME in the autumn 2000. The SCV was then followed for close to 1 year, and the associated mesoscale eddy is identified without ambiguity from altimetry even later until February 2002 near $42.5^{\circ} \mathrm{N}, 20^{\circ} \mathrm{W}$-so 3 yr after formation. This shows that these eddies can have a very long life in the eastern Atlantic. The SCV withstood the interaction with bottom topography (the Biscay-Azores ridge segment) and with other dynamical structures. It does not seem to be much affected by horizontal mixing, as witnessed by the transition zone in the water masses on the outskirts of the SCV, or vertical mixing that could happen below its core associated with near-inertial critical layers, although this should contribute to its eventual decay (Kunze et al. 1995). Such a long life was also inferred for other mode water eddies in the subtropical eastern Atlantic (Pingree 1996; Pingree and Garcia-Soto 2004).

The SCV was embedded in a larger mesoscale eddy around $200 \mathrm{~km}$ or bigger in diameter and presenting a positive sea level anomaly (SLA) exceeding $10 \mathrm{~cm}$, easily detectable with satellite altimeters, at least since February 2001. The SCV and the mesoscale eddy do not share a similar vertical structure. We expect that de- spite the different vertical structure, the SCV is trapped by the mesoscale potential vorticity distribution, somehow sheltering the SCV from external influence. This is somewhat reminiscent of the observations of a core and anticyclonic mesoscale eddy formed near the Canaries (Sangrà et al. 2005), albeit in that case those were surface-trapped structures. At times, we find suggestions that the SCV might not be located at the center of the mesoscale eddy, possibly as a result of interaction with bathymetry. The earlier or later evolutions of the SCV and the larger mesoscale eddy are, however, not necessarily linked, and the mesoscale eddy is clearly not as coherent and stable as the SCV. The total displacement of the entire structure over the whole period of observations, which lasted about a year, was quite small, probably as a result of interaction with a shallow segment of the Azores-Biscay ridge.

Water properties in the SCV core point out to an origin outside the POMME domain and more likely in the northern Bay of Biscay area. This is, therefore, an original pathway of ventilation in the intergyre region, quite different from what was usually found during the POMME surveys, which was caused by the seasonal retreat of the winter mixed layer in March 2001, either locally or further to the north (Gaillard et al. 2005; Reverdin et al. 2005). Interestingly, this is a pathway not reproduced in the high-resolution numerical modeling done for POMME (Paci et al. 2005).

We did not find these water mass characteristics and low mode water stratification in other POMME eddies. However, this is based on a somewhat coarse hydrographic survey and set of sections, which might have missed other such SCVs, whereas the float trajectories near $400 \mathrm{~m}$ (Le Cann et al. 2005) identify other structures with a high negative vorticity reaching almost $-0.5 f$ near the eddy center.

Acknowledgments. The POMME experiment was funded by the INSU/PATOM and PROOF programs and could be realized with the oceanographic cruises on the R/V Thalassa, R/V Atalante, and R/V d'Entrecasteaux thanks to the devoted crew and scientific parties. C. Rouault, A. Lourenço, P. Testor, N. Cortes, and L. Gourmelen prepared the floats. M. Rafizadeh and C. Richez processed the LOCEAN floats; T. Reynaud, A. Faisant, L. Gourmelen, and G. Roudaut processed the LPO/CMO floats; and Sandra Sequeira processed the CTD data and carried out some of the analyses. The acoustic network was maintained in cooperation between LOCEAN in Paris, LPO, and SHOM in Brest. The two moorings, NE and NW, were implemented by C. Marec (DT-INSU). JCG, BLC, LP, and GR are 


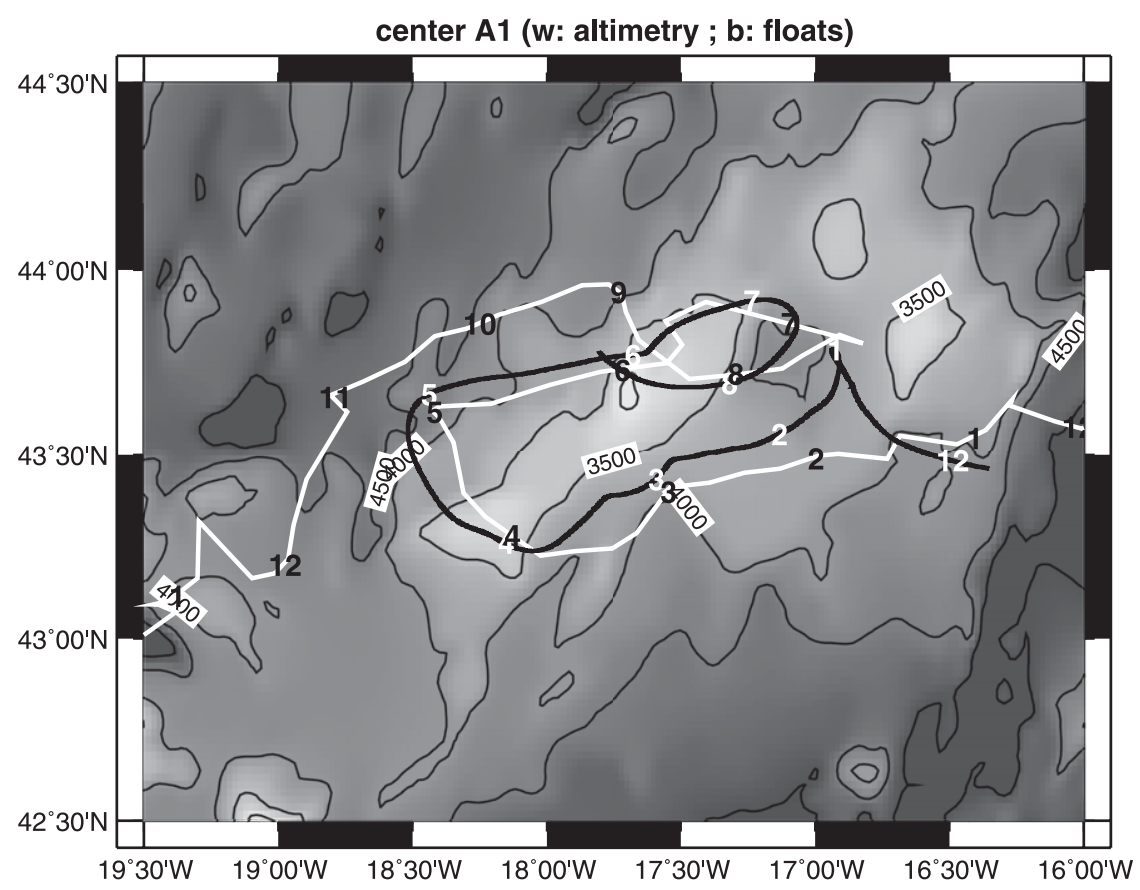

FIG. A1. The A1 eddy center position from November 2000 to September 2001 superimposed on bottom topography (lighter for shallower depths). The month (number) is reported on the curve at each beginning of month. White curve: based on weekly altimetry maps; black curve: a smoothed version of SCV position of Fig. 1.

supported by CNRS, MA by SHOM, and PL by IFREMER. The altimeter products were produced by the CLS Space Oceanography Division as part of the Environment and Climate EU AGORA (ENV4 CT9560113) and refer to the scientific references given above and to the AVISO and CERSAT handbooks. Finally, we thank the two referees and the editor for their thoughtful comments.

\section{APPENDIX}

\section{Eddy A1 Trajectory}

It is possible to locate a center of eddy A1 from the CLS altimetric-based product of absolute sea surface height. This is done weekly by checking the position of the highest mapped surface sea level in the vicinity of previous or older weekly estimates. The trajectory of A1 that is thus plotted (Fig. A1) does not show the anticyclonic loops that are witnessed by the floats in the SCV (Fig. 1). This is not surprising, as the maps are done by combining data over a fairly large time window with a 20day decorrelation time scale and thus would not be able to capture oscillations on that frequency. Interestingly, when smoothing (over 40 days) the trajectory of the SCV center, we obtain a trajectory presenting many similari- ties with the altimeter-derived trajectory, in particular from February through August 2001 (Fig. A1).

Earlier from mid-November 2000 to mid-February 2001, the smoothed trajectory of the SCV center is somewhat to the west or northwest of the altimeterderived center, with a spatial separation often larger than $50 \mathrm{~km}$. This large separation over a fairly long period is surprising, as it is too large to be related to the difference between subsurface and surface geostrophic center positions. After 15 January, it is also a time when the SCV is not drifting fast and, therefore, should be expected to be close to the eddy center. During this period from November 2000 to January 2001, the altimetric maps do not show a symmetric eddy. This also could be an indication of the presence of more than one eddy with a satellite sampling or mapping scales not sufficient to separate them. The differences highlight the difficulty of using satellite altimetry to precisely locate the core of eddies such as A1. However, it clearly captures the large-scale behavior of the eddy and the eddy trapping for more than six months close to the rise in the Azores-Biscay ridge.

\section{REFERENCES}

Assenbaum, M., and G. Reverdin, 2005: Near real-time analyses of the mesoscale circulation during the POMME experiment. Deep-Sea Res., 52, 1345-1373. 
Bouruet-Aubertot, P., H. Mercier, F. Gaillard, and P. Lherminier, 2005: Evidence of strong inertia-gravity wave activity during the POMME experiment. J. Geophys. Res., 110, C07S06, doi:10.1029/2004JC002747.

Bower, A., and Coauthors, 2002: Directly measured mid-depth circulation in the northeastern North Atlantic Ocean. Nature, 419, 603-607.

de Boyer Montégut, C., G. Madec, A. S. Fischer, A. Lazar, and D. Iudicone, 2004: Mixed layer depth over the global ocean: An examination of profile data and a profile-based climatology. J. Geophys. Res., 109, C12003, doi:10.1029/ 2004JC002378.

Ducet, N., P. Y. Le Traon, and G. Reverdin, 2000: Global highresolution mapping of ocean circulation from TOPEX/ Poseidon and ERS-1 and -2. J. Geophys. Res., 105 (C8), 19 477-19 498.

Fernández, C., P. Raimbault, G. Caniaux, N. Garcia, and P. Rimmelin, 2005a: Influence of mesoscale eddies on nitrate distribution during the POMME program in the northeast Atlantic Ocean. J. Mar. Syst., 55, 155-175.

$\longrightarrow$, — , and N. Garcia, 2005b: An estimation of annual new production and carbon fluxes in the northeast Atlantic Ocean during 2001. J. Geophys. Res., 110, C07S13, doi:10.1029/ 2004JC002616.

Frolov, S. A., G. G. Sutyrin, G. D. Rowe, and L. M. Rothstein, 2004: Loop current eddy interaction with the western boundary in the Gulf of Mexico. J. Phys. Oceanogr., 34, 2223 2237.

Gaillard, F., H. Mercier, and C. Kermabon, 2005: A synthesis of the POMME physical data set: One year monitoring of the upper layer. J. Geophys. Res., 110, C07S07, doi:10.1029/ 2004JC002764.

Garcia-Soto, C., R. D. Pingree, and L. Valdés, 2002: Navidad development in the southern Bay of Biscay: Climate change and swoddy structure from remote sensing and in situ measurements. J. Geophys. Res., 107, 3118, doi:10.1029/ 2001JC001012.

Kunze, E., 1986: The mean and near-inertial velocity fields in a warm-core ring. J. Phys. Oceanogr., 16, 1444-1461.

— , R. W. Schmitt, and J. M. Toole, 1995: The energy balance in a warm-core ring's near-inertial critical layer. J. Phys. Oceanogr., 25, 942-957.

Le Cann, B., K. G. Speer, A. Serpette, J. Paillet, and T. Reynaud, 1999: Lagrangian observations in the intergyre northeast Atlantic during the ARCANE and EUROFLOAT projects: Early results. International WOCE Newsletter, No. 34, WOCE International Project Office, Southampton, United Kingdom, 25-27.

— , M. Assenbaum, J.-C. Gascard, and G. Reverdin, 2005: Observed mean and mesoscale upper ocean circulation in the midlatitude northeast Atlantic. J. Geophys. Res., 110, C07S05, doi:10.1029/2004JC002768.

Le Groupe Tourbillon, 1983: The Tourbillon experiment: A study of a mesoscale eddy in the eastern North Atlantic. Deep-Sea Res., 30A, 475-511.

Le Traon, P. Y., G. Dibarbourne, and N. Ducet, 2001: Use of a high-resolution model to analyze the mapping capabilities of multiple-altimeter missions. J. Atmos. Oceanic Technol., 18, 1277-1288.

Lilly, J. M., and J. C. Gascard, 2006: Wavelet ridge diagnosis of time-varying elliptical signals with application to an oceanic eddy. Nonlinear Processes Geophys., 13, 467-483.
Maixandeau, A., and Coauthors, 2005: Microbial community production, respiration, and structure of the microbial food web of an ecosystem in the northeastern Atlantic Ocean. J. Geophys. Res., 110, C07S17, doi:10.1029/ 2004JC002694.

Martin, A. P., I. P. Wade, K. J. Richards, and K. J. Heywood, 1998: The PRIME eddy. J. Mar. Res., 56, 439-462.

McGillicuddy, D. J., Jr., and Coauthors, 2007: Eddy/wind interactions stimulate extraordinary mid-ocean plankton blooms. Science, 316, 1021-1026.

McWilliams, J. C., 1985: Submesoscale, coherent vortices in the ocean. Rev. Geophys., 23, 165-182.

, and G. Flierl, 1979: On the evolution of isolated, nonlinear vortices. J. Phys. Oceanogr., 9, 1155-1181.

Mémery, L., G. Reverdin, J. Paillet, and A. Oschlies, 2005: Introduction to the POMME special section: Thermoclineventilation and biogeochemical tracer distribution in the northeast Atlantic Ocean and impact of mesoscale dynamics. J. Geophys. Res., 110, C07S01, doi:10.1029/ $2005 \mathrm{JC} 002976$.

Merlivat, L., M. Gonzalez Davila, G. Caniaux, J. Boutin, and G. Reverdin, 2009: Mesoscale and diel to monthly variability of $\mathrm{CO}_{2}$ and carbon fluxes at the ocean surface in the northeastern Atlantic. J. Geophys. Res., 114, C03010, doi:10.1029/ 2007JC004657.

Paci, A., G. Caniaux, M. Gavart, H. Giordani, M. Lévy, L. Prieur, and G. Reverdin, 2005: A high-resolution simulation of the ocean during the POMME experiment: Simulation results and comparison with observations. J. Geophys. Res., 110, C07S09, doi:10.1029/2004JC002712.

Paillet, J., 1999: Central water vortices of the eastern North Atlantic. J. Phys. Oceanogr., 29, 2487-2503.

— B. Be Cann, X. Carton, Y. Morel, and A. Serpette, 2002: Dynamics and evolution of a northern meddy. J. Phys. Oceanogr., 32, 55-79.

Pingree, R. D., 1996: A shallow subtropical subducting westward propagating eddy (Swesty). Philos. Trans. Roy. Soc. London, A354, 979-1026.

, and B. Le Cann, 1992: Anticyclonic eddy X91 in the southern Bay of Biscay, May 1991 to February 1992. J. Geophys. Res., 97 (C9), 14 353-14 367.

_- and B. Sinha, 1998: Dynamical topography (ERS-1/2 and sea truth) of subtropical ring (STORM 0) in the storm corridor $\left(32-34^{\circ} \mathrm{N}\right.$, eastern basin, North Atlantic Ocean). J. Mar. Biol. Assoc. U.K., 78, 351-376.

—_, and C. Garcia-Soto, 2004: Annual westward propagating anomalies near $26^{\circ} \mathrm{N}$ and eddy generation south of the Canary Islands: Remote sensing (altimeter/SeaWiFS) and in situ measurement. J. Mar. Biol. Assoc. U.K., 84, 11051115.

Read, J. F., and R. T. Pollard, 2001: A long-lived eddy in Iceland Basin 1998. J. Geophys. Res., 106, 11 411-11 421.

Reverdin, G., M. Assenbaum, and L. Prieur, 2005: Eastern North Atlantic mode waters during POMME (September 2000-2001). J. Geophys. Res., 110, C07S04, doi:10.1029/ 2004JC002613.

— E. Kestenare, C. Frankignoul, and T. Delcroix, 2007: In situ surface salinity in the tropical and subtropical Atlantic Ocean. Part I. Large scale variability. Prog. Oceanogr., 73, 311-340

Richardson, P., M. McCartney, and C. Maillard, 1991: A search for meddies in historical data. Dyn. Atmos. Oceans, 15, 241-265. 
A. S. Bower, and W. Zenk, 2000: A census of Meddies tracked by floats. Prog. Oceanogr., 45, 209-250.

Sangrà, P., and Coauthors, 2005: Life history of an anticyclonic eddy. J. Geophys. Res., 110, C03021, doi:10.1029/ 2004JC002526.

Stammer, D., H.-H. Hinrichsen, and R. H. Käse, 1991: Can meddies be detected by satellite altimetry? J. Geophys. Res., 96 (C4), 7005-7014. van Aken, H. M., 2001: The hydrography of the mid-latitude northeast Atlantic Ocean-Part III: The subducted thermocline water mass. Deep-Sea Res. I, 48, 237-267.

Visbeck, M., 2002: Deep velocity profiling using Lowered Acoustic Doppler Current Profilers: Bottom track and inverse solutions. J. Atmos. Oceanic Technol., 19, 794-807.

Wade, I. P., and K. J. Heywood, 2001: Tracking the PRIME eddy using satellite altimetry. Deep-Sea Res. II, 48, 725-737. 